\title{
The present and future of medical radionuclide production
}

\author{
By S. M. Qaim* \\ Institut für Neurowissenschaften und Medizin, INM-5: Nuklearchemie, Forschungszentrum Jülich GmbH, 52425 Jülich, Germany
}

(Received January 18, 2012; accepted in revised form May 4, 2012)

(Published online July 30, 2012)

\begin{abstract}
Reactor and cyclotron production of medical radionuclides / $\gamma$-ray emitters for SPECT / Positron emitters for PET / Corpuscular radiation emitters for internal radiotherapy / Low and intermediate energy nuclear reactions /

Radionuclide generators / Future directions
\end{abstract}

\begin{abstract}
Summary. Medical radionuclide production technology is well established. Both reactors and cyclotrons are utilized for production; the positron emitters, however, are produced exclusively using cyclotrons. A brief survey of the production methods of most commonly used diagnostic and therapeutic radionuclides is given. The emerging radionuclides are considered in more detail. They comprise novel positron emitters and therapeutic radionuclides emitting low-range electrons and $\alpha$-particles. The possible alternative production routes of a few established radionuclides, like ${ }^{68} \mathrm{Ga}$ and ${ }^{99 \mathrm{~m}} \mathrm{Tc}$, are discussed. The status of standardisation of production data of the commonly used as well as of some emerging radionuclides is briefly mentioned. Some notions on anticipated future trends in the production and application of radionuclides are considered.
\end{abstract}

\section{Introduction}

Radioactivity is unique in the sense that, in spite of its hazardous nature, it finds application in medicine both in diagnosis and therapy [cf. 1]. Each application, however, demands a special type of radionuclide. For in vivo diagnostic investigations involving organ imaging, for example, radionuclides are required that can be efficiently detected from outside of the body. To this end, short-lived $\gamma$-ray emitters, like ${ }^{99 \mathrm{~m}} \mathrm{Tc}$ and ${ }^{123} \mathrm{I}$, and positron emitters, like ${ }^{11} \mathrm{C}$ and ${ }^{18} \mathrm{~F}$, are commonly used, the former finding application in Single Photon Emission Computed Tomography (SPECT) and the latter in Positron Emission Tomography (PET). The underlying principle in diagnostic nuclear medicine is that the radiation dose to the patient is as low as possible, compatible with the required quality of imaging and the diagnostic advantage in comparison to non-radioactive methods. Thus a complete set of decay data of a radionuclide is required to be able to calculate the radiation dose which plays a very important role in its choice for a diagnostic medical application.

\footnotetext{
*E-mail: s.m.qaim@fz-juelich.de.

Co-ordinating Editor of the Journal.
}

The therapeutic application of radioactivity involves either external radiation therapy or internal radiotherapy. Whereas for the former, radionuclides emitting energetic $\beta^{-}$particles or hard $\gamma$-rays are commonly used, for example ${ }^{60} \mathrm{Co}\left(T_{1 / 2}=5.27 \mathrm{a}\right),{ }^{137} \mathrm{Cs}\left(T_{1 / 2}=30.17 \mathrm{a}\right)$ and ${ }^{192} \mathrm{Ir}$ $\left(T_{1 / 2}=73.8 \mathrm{~d}\right)$, the spectrum of radionuclides required in internal radionuclide therapy (endotherapy) is very broad. Since in this case a localised, well-defined radiation dose needs to be deposited in a malignant or inflammatory tissue, radionuclides emitting low-range highly-ionising radiation, i.e. $\alpha$ or $\beta^{-}$particles, conversion and/or Auger electrons, are of great interest.

The medical radionuclide production technology is well developed and is pursued both at commercial centres and some nuclear science research institutes. However, besides routine production and medical application of radionuclides, constant research work is going on around the world to improve the existing production methodologies of some established radionuclides as well as to develop novel radionuclides for new medical applications. Some thoughts and efforts are also constantly devoted to future development of this technology to meet the challenges of new approaches in medical investigations.

The production of radionuclides is carried out using nuclear reactors [for reviews $c f .2,3$ ] and accelerators/cyclotrons [for a review $c f$. 4]. The reactor production generally leads to neutron excess radionuclides. They mostly decay by $\beta^{-}$emission and are therefore especially suitable for radiotherapy. The cyclotron produced radionuclides, on the other hand, are mainly neutron deficient and decay by electron capture (EC) or $\beta^{+}$emission. They are therefore particularly useful for diagnostic studies. The positron emitters can be produced only at cyclotrons. For production of some nuclides both nuclear reactors and cyclotrons are extensively used. In other words, their roles are to be regarded as complementary. Worldwide there exist about 400 research reactors and about 500 cyclotrons. Most of them are at least partly used for production of medically useful radionuclides. The radionuclide production technology today has thus become an integral part of modern nuclear medicine and its future prospects also appear to be bright.

This article deals with three aspects of medical radionuclide production technology. In the first part, the routine production for state-of-the-art patient care is briefly outlined; in the second, the on-going new developments are discussed in some detail; and in the third, some emerging thoughts 
relevant to the future perspectives of this technology are considered.

\section{Present status of radionuclide production technology}

The radionuclides commonly used in medicine and in drug development are listed in Table 1, together with their decay properties and production routes $[c f .1,5]$. They are divided in four groups depending on the function they serve. Each group is discussed below.

\subsection{Soft $\beta^{-}$emitters for in vitro studies}

In this group the most important radionuclides include ${ }^{3} \mathrm{H}$ $\left(T_{1 / 2}=12.3 \mathrm{a}\right),{ }^{14} \mathrm{C}\left(T_{1 / 2}=5730 \mathrm{a}\right)$ and ${ }^{125} \mathrm{I}\left(T_{1 / 2}=59.4 \mathrm{~d}\right)$. They are available in large quantities in all parts of the world. Over the last 60 years, the radionuclides ${ }^{3} \mathrm{H}$ and ${ }^{14} \mathrm{C}$ have played a very important role in biochemistry for enhancing our understanding of physiological functions of molecules and radiopharmaceuticals (drug development research). This was possible due to the relatively simple method of measurement of their radioactivity via liquid scintillation counting. The radionuclide ${ }^{125} \mathrm{I}$ with its low-energy emissions is very well suited for autoradiography and is commonly used in radioimmunoassay or receptor binding studies.

All the three radionuclides mentioned above are produced in a nuclear reactor: Tritium via the ${ }^{6} \operatorname{Li}(n, \alpha)$-reaction on a $\mathrm{Li}$ or $\mathrm{LiF}$ target, ${ }^{14} \mathrm{C}$ through the ${ }^{14} \mathrm{~N}(n, p)$-reaction on an AlN target, and ${ }^{125} \mathrm{I}$ using the ${ }^{124} \mathrm{Xe}(n, \gamma){ }^{125} \mathrm{Xe} \rightarrow{ }^{125} \mathrm{I}$ process by irradiating ${ }^{\text {nat }} \mathrm{Xe}$ or enriched ${ }^{124} \mathrm{Xe}$ filled in an Al-capsule. Tritium is generally available as tritium gas or tritiated water, ${ }^{14} \mathrm{C}$ as ${ }^{14} \mathrm{CO}_{2}$ or $\mathrm{Ba}^{14} \mathrm{CO}_{3}$, and ${ }^{125} \mathrm{I}$ as ${ }^{125} \mathrm{I}^{-}$.

In addition to the three major soft $\beta^{-}$emitting radionuclides mentioned above, two other soft $\beta^{-}$emitting nuclides, namely ${ }^{33} \mathrm{P}\left(T_{1 / 2}=25.3 \mathrm{~d} ; E_{\beta^{-}}=248 \mathrm{keV}\right)$ and ${ }^{35} \mathrm{~S}$ $\left(T_{1 / 2}=87.5 \mathrm{~d} ; E_{\beta^{-}}=167 \mathrm{keV}\right)$, also find some limited application involving in vitro investigations. Both are produced in the no-carrier-added form in a high fast flux nuclear reactor, the former via the ${ }^{33} \mathrm{~S}(n, p){ }^{33} \mathrm{P}$ reaction on isotopically enriched ${ }^{33} \mathrm{~S}$ and the latter through the ${ }^{35} \mathrm{Cl}(n, p){ }^{35} \mathrm{~S}$ reaction on a $\mathrm{KCl}$ target $[c f .6]$. The radionuclides ${ }^{33} \mathrm{P}$ and ${ }^{35} \mathrm{~S}$ are generally available as $\mathrm{H}_{3}{ }^{33} \mathrm{PO}_{4}$ and $\mathrm{H}_{2}{ }^{35} \mathrm{SO}_{4}$, respectively, besides other forms.

\subsection{Gamma emitters for SPECT}

The number of $\gamma$-ray emitters which have found some application in imaging using gamma cameras is relatively large. However, with the advent of SPECT tomographs, it became incumbent to use radionuclides emitting either only one $\gamma$-ray or at least one predominant $\gamma$-ray within the energy range of $100-200 \mathrm{keV}$. The choice was thus reduced to five radionuclides, namely ${ }^{67} \mathrm{Ga}\left(T_{1 / 2}=3.26 \mathrm{~d}\right),{ }^{99 \mathrm{~m}} \mathrm{Tc}$ $\left(T_{1 / 2}=6.0 \mathrm{~h}\right),{ }^{111} \mathrm{In}\left(T_{1 / 2}=2.8 \mathrm{~d}\right),{ }^{123} \mathrm{I}\left(T_{1 / 2}=13.2 \mathrm{~h}\right)$ and ${ }^{201} \mathrm{Tl}\left(T_{1 / 2}=3.06 \mathrm{~d}\right)$. The radionuclide ${ }^{99 \mathrm{~m}} \mathrm{Tc}$ is by far the most commonly used SPECT radionuclide. It ideally emits a $141 \mathrm{keV}$ photon and causes the least radiation dose to the patient. It is almost always available in a clinic via the ${ }^{99} \mathrm{Mo} /{ }^{99 \mathrm{~m}} \mathrm{Tc}$ generator system. Furthermore, by virtue of its versatile complex formation chemistry, labelling methods are established to rather easily bind it to various compounds. This characteristic has led to development of several robust labelling kits. The eluted ${ }^{99 \mathrm{~m}} \mathrm{Tc}$ as pertechnetate is transferred to an ampoule containing an appropriate lyophilised mixture of reagents. On shaking, the labelling of given ligands with ${ }^{99 \mathrm{~m}} \mathrm{Tc}$ occurs in a specific configuration and the product is then ready for human use. Also the radionuclide ${ }^{123} \mathrm{I}$ is commonly used. However, due to its lesser availability and higher cost, ${ }^{123} \mathrm{I}$ is much less broadly used than ${ }^{99 \mathrm{~m}} \mathrm{Tc}$. The third radionuclide, viz. ${ }^{201} \mathrm{Tl}$, is extensively used for myocardial perfusion measurements. The remaining two radionuclides, namely ${ }^{67} \mathrm{Ga}$ and ${ }^{111} \mathrm{In}$ are less commonly used as SPECT agents. They are partly being considered for therapeutic applications because they emit a large number of Auger electrons.

As mentioned above, ${ }^{99 \mathrm{~m}} \mathrm{Tc}$ is available via the ${ }^{99} \mathrm{Mo} /$ ${ }^{99 \mathrm{~m}} \mathrm{Tc}$ generator. An $\mathrm{Al}_{2} \mathrm{O}_{3}$-column is loaded with ${ }^{99} \mathrm{Mo}$ and the daughter activity is periodically removed by elution with saline. The parent nuclide ${ }^{99} \mathrm{Mo}\left(T_{1 / 2}=66.0 \mathrm{~h}\right)$ is produced at a nuclear reactor, and two routes are possible: ${ }^{98} \mathrm{Mo}(n, \gamma){ }^{99} \mathrm{Mo}$ and ${ }^{235} \mathrm{U}(n, f){ }^{99} \mathrm{Mo}$. The cross section of the $(n, \gamma)$-reaction is relatively small and due to the use of ${ }^{\text {nat }} \mathrm{Mo}$ (with a ${ }^{98} \mathrm{Mo}$ content of $24.13 \%$ ) as target material, the specific activity of the ${ }^{99}$ Mo produced is low. Thus, because of the heavy loading of the $\mathrm{Al}_{2} \mathrm{O}_{3}$-generator column with stable molybdenum, in spite of the rather big dimensions of the column, the risk of breakthrough of Mo is high and ${ }^{99 \mathrm{~m}} \mathrm{Tc}$ eluate volumes are large. Somewhat higher specific activity is achieved using a high-flux nuclear reactor. However, such reactors are seldom available for radionuclide production. Attempts have been made to enrich ${ }^{99}$ Mo via a Szilard Chalmers process [ $c f .7]$ but the separation yields are low. Furthermore, some gel and distillation generators have been developed $[c f .8,9]$ but their overall efficiencies are not comparable to that of the alumina column generator. In view of the situation, combined with the fact that for production purposes irradiations are mostly done at medium-flux reactors, the method of choice for production of ${ }^{99}$ Mo for medical use is the fission process.

The cross section for the thermal neutron induced fission of ${ }^{235} \mathrm{U}$ is 596 barn and the cumulative yield of ${ }^{99} \mathrm{Mo}$ is $6.16 \%$; thus $\mathrm{TBq}$ amounts of ${ }^{99} \mathrm{Mo}$ can be produced per batch. Although the chemical processing of the irradiated target is very laborious, especially in view of the high demand on the quality assurance of the separated product, only the fission process is accepted because it leads to ${ }^{99} \mathrm{Mo}$ of very high specific activity. In fact the fission produced ${ }^{99} \mathrm{Mo}$ on an $\mathrm{Al}_{2} \mathrm{O}_{3}$ column is regarded as a gold standard generator system. The eluted ${ }^{99 \mathrm{~m}}$ Tc occurs as pertechnetate.

The ease and success associated with the generator elution of ${ }^{99 \mathrm{~m}} \mathrm{Tc}$ and the development of kit formulation of some very important ${ }^{99 \mathrm{~m}}$ Tc-labelled diagnostic agents has led to the very wide use of ${ }^{99 \mathrm{~m}} \mathrm{Tc}$. The fission ${ }^{99} \mathrm{Mo}$ is produced only at a few advanced centres and is then distributed to various laboratories around the world where the generator loading is undertaken (dispensing). The generators are then sent to regional clinics. It is estimated that worldwide 35 million patients per year are subjected to diagnostic investigations with ${ }^{99 \mathrm{~m}} \mathrm{Tc}[c f .10]$. Despite this success story and the demonstrated need for continuous availability of this radionuclide, its future supply appears to be somewhat 
Table 1. Commonly used medical radionuclides and their production methods (decay data taken from www.nndc.bnl/ nudat $2 /$ ).

\begin{tabular}{|c|c|c|c|c|c|}
\hline Radionuclide & $T_{1 / 2}$ & 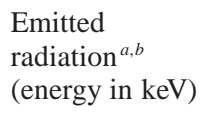 & Production process & $\begin{array}{l}\text { Energy } \\
\text { range } \\
{[\mathrm{MeV}]}\end{array}$ & $\begin{array}{c}\text { Typical } \\
\text { batch yield } \\
\text { [GBq] }\end{array}$ \\
\hline \multicolumn{6}{|c|}{ Soft $\beta^{-}$emitters for in vitro studies } \\
\hline${ }^{3} \mathrm{H}$ & $12.3 \mathrm{a}$ & $\beta^{-}$ & ${ }^{6} \mathrm{Li}(n, \alpha)$ & $c$ & $>500$ \\
\hline${ }^{14} \mathrm{C}$ & $5730 a$ & $\beta^{-}$ & ${ }^{14} \mathrm{~N}(n, p)$ & $c$ & 20 \\
\hline${ }^{125} \mathrm{I}$ & $59.4 \mathrm{~d}$ & $\begin{array}{l}\text { Auger electrons } \\
\text { (and X-rays) }\end{array}$ & ${ }^{124} \mathrm{Xe}(n, \gamma){ }^{125} \mathrm{Xe} \rightarrow{ }^{125} \mathrm{I}$ & $c$ & 50 \\
\hline \multicolumn{6}{|c|}{$\gamma$-emitters for SPECT } \\
\hline${ }^{67} \mathrm{Ga}$ & $3.26 \mathrm{~d}$ & $\gamma(93) \gamma(185)$ & ${ }^{68} \mathrm{Zn}(p, 2 n)^{67} \mathrm{Ga}$ & $26 \rightarrow 18$ & 50 \\
\hline $\begin{array}{l}{ }^{99} \text { Mo } \\
\text { (generator) } \\
\downarrow\end{array}$ & $2.75 \mathrm{~d}$ & $\beta^{-}$ & $\left.{ }^{235} \mathrm{U}(n, f)\right)^{99} \mathrm{Mo}$ & $c$ & $>10^{3}$ \\
\hline${ }^{99 \mathrm{~m}} \mathrm{Tc}$ & $6.0 \mathrm{~h}$ & & ${ }^{98} \mathrm{Mo}(n, \gamma){ }^{99} \mathrm{Mo}$ & $c$ & 10 \\
\hline \multirow{3}{*}{${ }^{123} \mathrm{I}$} & $13.2 \mathrm{~h}$ & $\gamma$ & ${ }^{123} \mathrm{Te}(p, n)$ & $14.5 \rightarrow 10$ & 20 \\
\hline & & & ${ }^{124} \mathrm{Xe}(p, x){ }^{123} \mathrm{Xe} \rightarrow{ }^{123} \mathrm{I}$ & $29 \rightarrow 23$ & $70^{e}$ \\
\hline & & & ${ }^{127} \mathrm{I}(p, 5 n){ }^{123} \mathrm{Xe} \rightarrow{ }^{123} \mathrm{I}$ & $65 \rightarrow 45$ & $70^{e}$ \\
\hline${ }^{111}$ In & $2.8 \mathrm{~d}$ & $\begin{array}{l}\gamma(173) \\
\gamma(247)\end{array}$ & ${ }^{112} \mathrm{Cd}(p, 2 n)^{111} \mathrm{In}$ & $25 \rightarrow 18$ & 50 \\
\hline${ }^{201} \mathrm{Tl}$ & $3.06 \mathrm{~d}$ & $\begin{array}{l}\mathrm{X} \text {-rays }(69-82) \\
\gamma(166)\end{array}$ & ${ }^{203} \mathrm{Tl}(p, 3 n)^{201} \mathrm{~Pb} \rightarrow{ }^{201} \mathrm{Tl}$ & $28 \rightarrow 20$ & $50^{f}$ \\
\hline
\end{tabular}

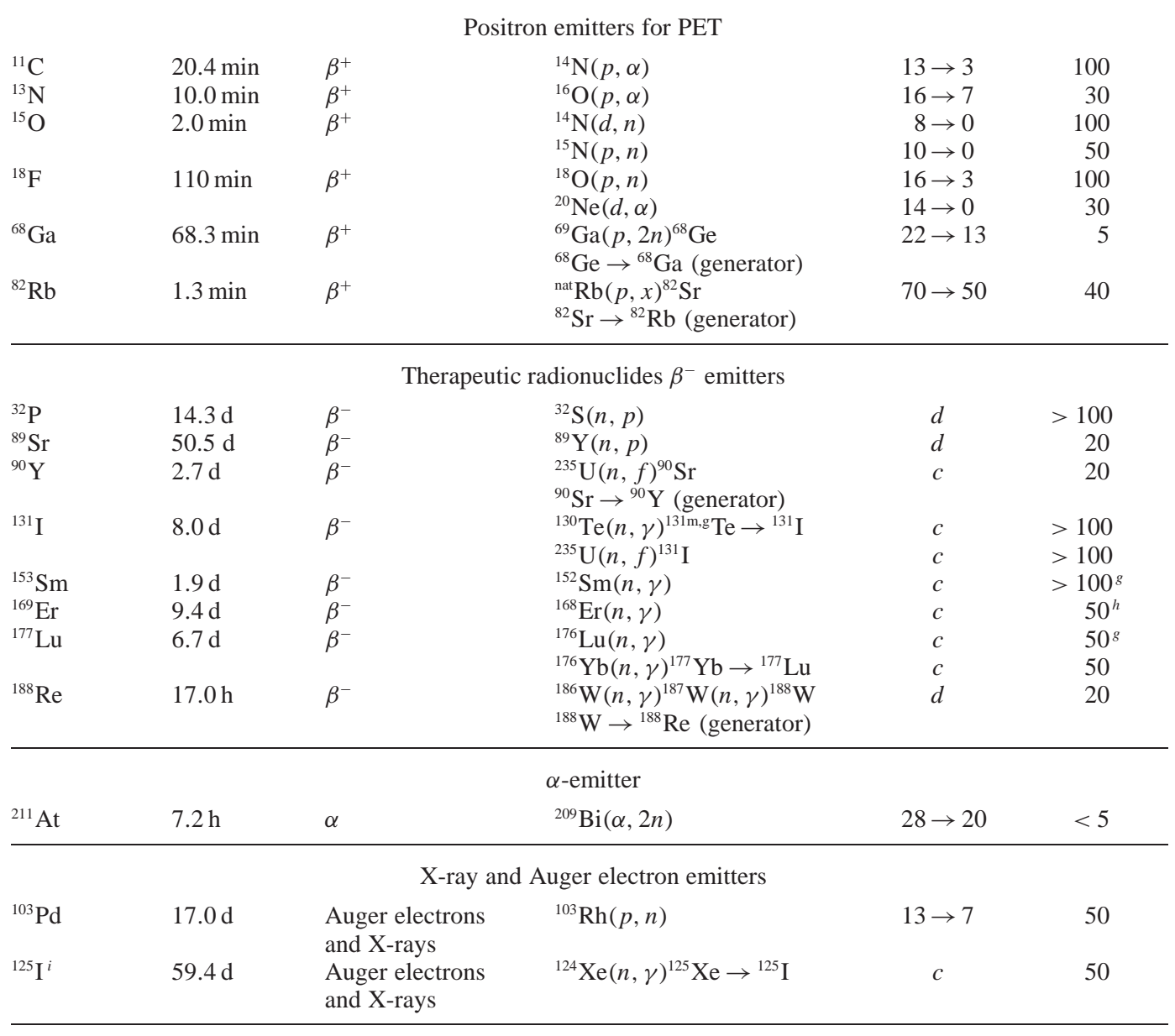

a: For $\beta^{-}, \beta^{+}$and $\alpha$-particles the values are maximum energies.

b: The $\gamma$-ray is used in SPECT studies. For PET studies annihilation radiation is used.

c: With reactor neutrons.

$\mathrm{d}$ : With neutrons in a high flux reactor.

e: ${ }^{123} \mathrm{I}$ yield after a $7 \mathrm{~h}$ decay of ${ }^{123} \mathrm{Xe}$.

f: ${ }^{201} \mathrm{Tl}$ yield after a $32 \mathrm{~h}$ decay of ${ }^{201} \mathrm{~Pb}$.

$\mathrm{g}$ : Product of moderate specific activity.

h: Product of low specific activity.

i: This radionuclide is also listed above under soft $\beta^{-}$emitters for in vitro investigations. 
jeopardised. On one hand the presently used reactors are ageing and there appears to be no planning for their replacement and, on the other, there is the risk of nuclear weapons' proliferation due to the use of highly enriched ${ }^{235} \mathrm{U}$ as the target material. Both these aspects demand a search for alternative methods of production and separation of ${ }^{99} \mathrm{Mo}$ and/or ${ }^{99 \mathrm{~m}} \mathrm{Tc}$. Considerable efforts are underway in this direction. They are discussed in detail below (Sect. 3.3).

For the production of the radionuclide ${ }^{123} \mathrm{I}$, about $25 \mathrm{nu}-$ clear processes have been investigated [cf.1]. Out of them only three are commonly used, mainly due to the level of the radionuclidic impurity associated with most of the processes. On a small cyclotron $(E<20 \mathrm{MeV})$ the reaction ${ }^{123} \mathrm{Te}(p, n)^{123} \mathrm{I}$ over the energy range $E_{\mathrm{p}}=14.5 \rightarrow 10 \mathrm{MeV}$ is utilized, provided a highly enriched ${ }^{123} \mathrm{Te}$-target is available. The yield of ${ }^{123} \mathrm{I}$ is, however, rather low. The separation of radioiodine is generally done via a dry distillation process $[c f .4]$.

The second method involves the production of the precursor ${ }^{123} \mathrm{Xe}\left(T_{1 / 2}=2.1 \mathrm{~h}\right)$ which decays to ${ }^{123} \mathrm{I}$. It demands a medium-sized cyclotron $(E \approx 30 \mathrm{MeV})$. Starting with highly enriched ${ }^{124} \mathrm{Xe}$ gas as target material, the precursor ${ }^{123} \mathrm{Xe}$ is produced via the processes ${ }^{124} \mathrm{Xe}(p, 2 n){ }^{123} \mathrm{Cs} \rightarrow$ ${ }^{123} \mathrm{Xe}$ and ${ }^{124} \mathrm{Xe}(p, p n){ }^{123} \mathrm{Xe}[c f .11]$. Over the optimum energy range of $E_{\mathrm{p}}=29 \rightarrow 23 \mathrm{MeV}$ the major contribution to the formation of ${ }^{123} \mathrm{I}$ is furnished by the $(p, 2 n)$ process. The level of the only radionuclidic impurity ${ }^{121} \mathrm{I}$ $\left(T_{1 / 2}=2.1 \mathrm{~h}\right)$ is negligibly small. However, if the incident proton energy exceeds $30 \mathrm{MeV}$, the cross section of the process ${ }^{124} \mathrm{Xe}(p, x){ }^{121} \mathrm{I}$ becomes appreciable [cf. 12]. The latter decays to long-lived ${ }^{121} \mathrm{Te}\left(T_{1 / 2}=154 \mathrm{~d}\right)$ which is a disadvantage. An energy control of the beam incident on the target is therefore mandatory. The activated xenon gas is allowed to decay for about $7 \mathrm{~h}$ and ${ }^{123} \mathrm{I}$ is then collected by rinsing the inner wall of the container. This method of production is now commonly used because it gives the purest product and is the only one accepted by regulations in most countries. The enriched target gas ${ }^{124} \mathrm{Xe}$ is relatively expensive. The technology related to irradiation and safe recovery of the target gas as well as an efficient removal of ${ }^{123} \mathrm{I}$ from the target wall is thus very demanding. This technology is, however, now commercially available.

The third method of production of ${ }^{123} \mathrm{I}$ utilizes the intermediate energy nuclear process ${ }^{127} \mathrm{I}(p, 5 n){ }^{123} \mathrm{Xe} \rightarrow{ }^{123} \mathrm{I}$, the optimum energy range being $E_{\mathrm{p}}=65 \rightarrow 45 \mathrm{MeV}$. The product ${ }^{123} \mathrm{Xe}$ is removed from the $\mathrm{NaI}$ target, collected in a vessel and is allowed to decay for about $7 \mathrm{~h}$. Thereafter ${ }^{123} \mathrm{I}$ is collected in a small volume by rinsing the inner wall of the vessel. This process leads to a high yield of ${ }^{123} \mathrm{I}$ but in this case the product contains about $0.25 \%{ }^{125} \mathrm{I}\left(T_{1 / 2}=59.4 \mathrm{~d}\right)$ as impurity.

The radioiodine produced by all the three methods occurs as iodide which is a suitable chemical form for subsequent labelling of organic compounds via substitution reactions.

The production of ${ }^{201} \mathrm{Tl}$ is mainly done via the route ${ }^{203} \mathrm{Tl}(p, 3 n)^{201} \mathrm{~Pb} \rightarrow{ }^{201} \mathrm{Tl}$, utilizing the energy range $E_{\mathrm{p}}=$ $28 \rightarrow 20 \mathrm{MeV}$ [cf.4]. The irradiation of ${ }^{\text {nat }} \mathrm{Tl}$ or ${ }^{203} \mathrm{Tl}$ is done at a medium-sized cyclotron and the chemical processing follows in two steps: first the precursor ${ }^{201} \mathrm{~Pb}\left(T_{1 / 2}=9.4 \mathrm{~h}\right)$ is separated and, after its decay for $32 \mathrm{~h}$, during which the maximum growth of ${ }^{201} \mathrm{Tl}$ occurs, the product is isolated as
${ }^{201} \mathrm{TlCl}$. It should be pointed out here that the target material thallium is toxic. The product ${ }^{201} \mathrm{Tl}$, however, is in no-carrier-added form and can therefore be safely used, provided the stringent quality control standards are fully complied with. Furthermore, ${ }^{201} \mathrm{Tl}$ is useful only in the monovalent form; the trivalent form is not effective for medical application [cf. 4].

The above mentioned two less commonly used SPECT radionuclides, namely ${ }^{67} \mathrm{Ga}$ and ${ }^{111} \mathrm{In}$, which are now also considered for Auger therapy (see below) are produced at a medium-sized cyclotron over the optimum energy range of $E_{\mathrm{p}}=25 \rightarrow 18 \mathrm{MeV}$ via the nuclear reactions ${ }^{68} \mathrm{Zn}(p, 2 n){ }^{67} \mathrm{Ga}$ and ${ }^{112} \mathrm{Cd}(p, 2 n){ }^{111} \mathrm{In}$, respectively [cf. 4]. In each case an enriched target is used and efficient methods of chemical purification have been worked out. The two radionuclides are commercially available in GBq amounts.

\subsection{Positron emitters for PET}

The number of positron-emitting radionuclides is large. For present day medical diagnostic imaging, the radionuclide used should have a short half-life, and emit only a low energy positron and possibly no high-energy $\gamma$-ray. Thus for routine PET investigations, mainly the short-lived organic positron emitters, viz. ${ }^{11} \mathrm{C}\left(T_{1 / 2}=20.4 \mathrm{~min}\right)$ and ${ }^{18} \mathrm{~F}$ $\left(T_{1 / 2}=110 \mathrm{~min}\right)$, and to a lesser extent ${ }^{15} \mathrm{O}\left(T_{1 / 2}=2 \mathrm{~min}\right)$ and ${ }^{13} \mathrm{~N}\left(T_{1 / 2}=10 \mathrm{~min}\right)$, are used. The radionuclides ${ }^{11} \mathrm{C}$, ${ }^{13} \mathrm{~N}$ and ${ }^{15} \mathrm{O}$ are generally used at the site of production. ${ }^{18} \mathrm{~F}$, on the other hand, is extensively employed for transport to nearby medical units having a PET but not a cyclotron. They can all be produced at low-energy cyclotrons. Besides those four positron emitters, two other short-lived positron emitters, namely ${ }^{68} \mathrm{Ga}\left(T_{1 / 2}=67.6 \mathrm{~min}\right)$ and ${ }^{82} \mathrm{Rb}$ $\left(T_{1 / 2}=1.3 \mathrm{~min}\right)$, widely used in diagnostic studies, are produced via generator systems. Their long-lived parents ${ }^{68} \mathrm{Ge}$ $\left(T_{1 / 2}=271 \mathrm{~d}\right)$ and ${ }^{82} \mathrm{Sr}\left(T_{1 / 2}=25.3 \mathrm{~d}\right)$, respectively, are produced through intermediate energy reactions.

The organic positron emitters are generally produced using low-energy reactions [for reviews $c f$. 1,13], e.g. ${ }^{11} \mathrm{C}$ via the ${ }^{14} \mathrm{~N}(p, \alpha)$-reaction, ${ }^{13} \mathrm{~N}$ through the ${ }^{16} \mathrm{O}(p, \alpha)$ reaction and ${ }^{18} \mathrm{~F}$ using the ${ }^{18} \mathrm{O}(p, n)$-reaction. For ${ }^{15} \mathrm{O}$ production via the ${ }^{14} \mathrm{~N}(d, n)$-reaction, and for electrophilic ${ }^{18} \mathrm{~F}$ production via the ${ }^{20} \mathrm{Ne}(d, \alpha)$-reaction, of course a deuteron beam is needed. If it is not available, the radionuclide ${ }^{15} \mathrm{O}$ can be produced using the ${ }^{15} \mathrm{~N}(p, n)$-reaction on highly enriched ${ }^{15} \mathrm{~N}$. On the other hand, for the production of ${ }^{15} \mathrm{O}$, in a few PET centres a small single particle cyclotron $\left(E_{\mathrm{d}}<4 \mathrm{MeV}\right)$ has also been successfully utilized.

Regarding the technical aspects of production of shortlived positron emitters, considerable attention has been devoted over the last 25 years to high-current targetry and chemical processing. For production of ${ }^{11} \mathrm{C}$ and ${ }^{15} \mathrm{O}$, for example, high-pressure gas targets have been developed, and the two radionuclides can be easily obtained in $100 \mathrm{GBq}$ quantities. The chemical form of the product coming out of the target depends on the composition of the target gas and the accumulated radiation dose. Thus precursors for labelling work with ${ }^{11} \mathrm{C}$ comprise ${ }^{11} \mathrm{CO}_{2},{ }^{11} \mathrm{CH}_{4}$ and increasingly ${ }^{11} \mathrm{CO}$, and with ${ }^{15} \mathrm{O}$ it is $\left[{ }^{15} \mathrm{O}\right] \mathrm{O}_{2}$. For the production of ${ }^{11} \mathrm{C}$ of high specific activity, special precautions are necessary since stable ${ }^{12} \mathrm{C}$ is present everywhere. The composition 
of the target body material, the purity of the filling gas and the quality of the used chemicals must meet the recommended specifications [ $c f$. 14]. For the production of ${ }^{13} \mathrm{~N}$ and ${ }^{18} \mathrm{~F}$, generally water targets are used. In the former case, natural water $\left(\mathrm{H}_{2}{ }^{16} \mathrm{O}\right)$ is employed and the species obtained is ${ }^{13} \mathrm{NO}_{3}{ }^{-}$; in the latter, enriched water $\left(\mathrm{H}_{2}{ }^{18} \mathrm{O}\right)$ is used and the species obtained is $\left[{ }^{18} \mathrm{~F}^{-}\right]$fluoride. The radionuclide ${ }^{18} \mathrm{~F}$ can now be produced in quantities up to $100 \mathrm{GBq}$ per target batch.

As mentioned above, the production of the parent nuclides of the two commonly used generator-produced $\beta^{+}$ emitters, namely ${ }^{68} \mathrm{Ga}$ and ${ }^{82} \mathrm{Rb}$, is done using intermediate energy reactions $\left[c f\right.$. 15]. The radionuclide ${ }^{68} \mathrm{Ge}$ is basically produced via the ${ }^{69} \mathrm{Ga}(p, 2 n){ }^{68} \mathrm{Ge}$ reaction since the cross section is rather high (see discussion below). However, due to its long half-life, the yield is low and high proton beam fluxes approaching the mA level are essential. Furthermore, long irradiations are required. It is partly obtained via the spallation of bromine or arsenic; however, the purification of the product is cumbersome. Due to the increasing significance of the $\beta^{+}$emitter ${ }^{68} \mathrm{Ga}$ (see discussion below), more concerted efforts are needed to ensure its continuous supply. The radionuclide ${ }^{82} \mathrm{Sr}$ is produced today mainly via the ${ }^{\text {nat }} \mathrm{Rb}(p, x n)$-process at $E_{\mathrm{p}}=70 \rightarrow 50 \mathrm{MeV}$. A consortium of laboratories collaborates in irradiations but the chemical processing is mainly done at Los Alamos. The purified ${ }^{82} \mathrm{Sr}$ is then distributed worldwide to prepare generators. Recently the available generator has come to some disrepute because of the breakthrough of the long-lived radiostrontium. Efforts to remediate this drawback are underway.

In recent years, PET imaging has been gaining enhanced significance because it leads to quantitative information on regional physiological and pharmacological activities by a molecular probe (labelled with a positron emitter) with high sensitivity and with a spatial resolution down to $1 \mathrm{~mm}$. The major impetus came through the production of ${ }^{18} \mathrm{~F}$ in large quantities via the ${ }^{18} \mathrm{O}(p, n){ }^{18} \mathrm{~F}$ reaction $[13,16]$ at a small cyclotron followed by a simplified method of nucleophilic substitution by ${ }^{18} \mathrm{~F}$ in organic molecules [17]. This led in particular to the preparation of the most frequently used PET-tracer 2-[ $\left[{ }^{18} \mathrm{~F}\right]$-fluoro-2-desoxy-D-glucose in large amounts [18]. This radiopharmaceutical is now extensively used in neurology, cardiology and oncology. It is estimated that worldwide a few million patients per year are treated using this radiopharmaceutical. Today, the whole PET technology (consisting of cyclotron, radionuclide production unit, and automated radiosynthesis apparatus) is commercially available. It is now reaching almost all corners of the globe.

\subsection{Radionuclides for internal radiotherapy}

As mentioned above, for internal radiotherapy $\beta^{-}, \alpha-$, Auger electron and X-ray emitters are of great interest $[c f .1,19]$. In the simplest case the radiation emitter is brought mechanically to the vicinity of the tumour to be treated. This type of therapy, known as brachytherapy, is commonly performed with ${ }^{192} \operatorname{Ir}\left(T_{1 / 2}=73.8 \mathrm{~d}\right)$ in the form of a wire, ${ }^{125} \mathrm{I}$ $\left(T_{1 / 2}=59.4 \mathrm{~d}\right)$ as a stent or ${ }^{103} \mathrm{Pd}\left(T_{1 / 2}=17.0 \mathrm{~d}\right)$ as a seed or a stent. In the case of ${ }^{192} \mathrm{Ir}$, the long-range $\beta^{-}$particles are effective but in the latter two cases, X-rays cause the ther- apeutic effect. After a given period the radioactive source is removed from the organ. A more common application is palliative therapy. Radionuclides like ${ }^{32} \mathrm{P}\left(T_{1 / 2}=14.3 \mathrm{~d}\right)$ and ${ }^{90} \mathrm{Y}\left(T_{1 / 2}=2.7 \mathrm{~d}\right)$, which are pure $\beta^{-}$emitters with rather high $\beta^{-}$energy, are introduced into joints and cavities as gels, glass microspheres or conglomerates. In case of small joints, ${ }^{169} \mathrm{Er}\left(T_{1 / 2}=9.4 \mathrm{~d}\right)$ with low $\beta^{-}$energy, is also used. Great care needs to be taken of the size of the particulate matter so that it does not ooze out of the cavity. The interaction of the radiation with the membrane covering the inner surface of the bone leads to palliative effect. A third variation of internal radiotherapy with $\beta^{-}$emitters involves the radiosynthesis of tumour seeking agents. For this purpose the radionuclides ${ }^{89} \mathrm{Sr}\left(T_{1 / 2}=50.5 \mathrm{~d}\right),{ }^{153} \mathrm{Sm}$ $\left(T_{1 / 2}=1.9 \mathrm{~d}\right),{ }^{177} \mathrm{Lu}\left(T_{1 / 2}=6.7 \mathrm{~d}\right),{ }^{188} \operatorname{Re}\left(T_{1 / 2}=17.0 \mathrm{~h}\right)$ and ${ }^{131} \mathrm{I}\left(T_{1 / 2}=8.0 \mathrm{~d}\right)$ are commonly used, the first four in case of bone metastases and the radionuclide ${ }^{131} \mathrm{I}$ in the form of iodide for treatment of thyroid tumours. Some other radionuclides in development are discussed separately.

Regarding the $\alpha$-emitters, to date many preclinical and some clinical studies have been performed using ${ }^{211} \mathrm{At}$ $\left(T_{1 / 2}=7.2 \mathrm{~h}\right)$. In fact the application of ${ }^{211} \mathrm{At}$ has a very long story, but it is still in the research phase. The radionuclide ${ }^{225} \mathrm{Ac}$ is potentially very important but it is still under development and is therefore treated in the next section. As far as Auger electron therapy is concerned, to date most of the experimental studies have been performed using ${ }^{125} \mathrm{I}$. The low range of the Auger electrons demands that the radiopharmaceutical, e.g. a labelled DNA compound, has the chance of reaching the cell nucleus in order to destroy the tumour. Thus ${ }^{125}$ I finds great interest not only for in vitro applications (see above) but is attractive for internal radiotherapy of tumours as well.

The production of the therapeutic radionuclides ${ }^{32} \mathrm{P}$ and ${ }^{89} \mathrm{Sr}$ with high specific activity is carried out in a nuclear reactor via the ${ }^{32} \mathrm{~S}(n, p){ }^{32} \mathrm{P}$ and ${ }^{89} \mathrm{Y}(n, p){ }^{89} \mathrm{Sr}$ reactions, respectively. The cross sections are rather low and therefore the yields are also low. Large amounts of ${ }^{89} \mathrm{Sr}$, for example, are produced at the high fast flux reactor RIAR in Dimitrovgrad, Russia, based on long irradiations of about 60 days $[c f .6]$. The radionuclide ${ }^{131} \mathrm{I}$ is typically produced via the fission process, but the precursor system ${ }^{130} \mathrm{Te}(n, \gamma){ }^{131 \mathrm{~m}, \mathrm{~g}} \mathrm{Te} \rightarrow{ }^{131} \mathrm{I}$, similar to the ${ }^{124} \mathrm{Xe}(n, \gamma){ }^{125} \mathrm{Xe} \rightarrow$ ${ }^{125} \mathrm{I}$ system described above for ${ }^{125} \mathrm{I}$, is also used. Both those radionuclides are thus obtained with high specific activity. For the production of the radionuclides ${ }^{90} \mathrm{Y}$ and ${ }^{188} \mathrm{Re}$, generator systems are used, viz. ${ }^{90} \mathrm{Sr} /{ }^{90} \mathrm{Y}$ and ${ }^{188} \mathrm{~W} /{ }^{188} \mathrm{Re}$. The parent radionuclide ${ }^{90} \mathrm{Sr}$ is separated from fission products, but the parent ${ }^{188} \mathrm{~W}$ is produced by double neutron capture on ${ }^{186} \mathrm{~W}$ in a high flux reactor, e.g. at Oak Ridge or Missouri, USA. Both the parents are long-lived and so special care is needed to assure that the daughter therapeutic radionuclides are isolated free of the parents. As expected, the specific activity of the two products is high, approaching almost theoretically maximum levels.

Regarding ${ }^{177} \mathrm{Lu}$ it should be pointed out that, besides the $6.71 \mathrm{~d}^{177} \mathrm{Lu}$, there exists a longer lived isomeric state ${ }^{177 \mathrm{~m}} \mathrm{Lu}$ $\left(T_{1 / 2}=160 \mathrm{~d}\right)$ which is undesirable. The direct production via the ${ }^{176} \mathrm{Lu}(n, \gamma)$-reaction leads to a mixture of both the isomers and since the abundance of the target isotope ${ }^{176} \mathrm{Lu}$ in ${ }^{\text {nat }} \mathrm{Lu}$ is only $2.59 \%$, despite the high capture cross sec- 
tion of $1780 \mathrm{~b}$, the specific activity of the product ${ }^{177} \mathrm{Lu}$ achieved is not high. In comparison, the indirect production route $\left.{ }^{176} \mathrm{Yb}(n, \gamma)\right)^{177} \mathrm{Yb} \rightarrow{ }^{177} \mathrm{Lu}$ not only gives ${ }^{177} \mathrm{Lu}$ in nocarrier-added form but also the contamination from ${ }^{177 \mathrm{~m}} \mathrm{Lu}$ is much lower [ $c f .20]$. The emphasis in recent years has been on improvement of chemical separations [ $c f .3]$.

In contrast to the above mentioned seven therapeutic radionuclides (i.e. ${ }^{32} \mathrm{P},{ }^{89} \mathrm{Sr},{ }^{90} \mathrm{Y},{ }^{125} \mathrm{I},{ }^{131} \mathrm{I},{ }^{177} \mathrm{Lu}$ and ${ }^{188} \mathrm{Re}$ ) which are produced with high specific activity via irradiations in a nuclear reactor, the yield and the specific activity of the radionuclide ${ }^{103} \mathrm{Pd}$, originally produced in a nuclear reactor via the reaction ${ }^{102} \mathrm{Pd}(n, \gamma){ }^{103} \mathrm{Pd}$, could not be improved. The production has therefore shifted from reactor to cyclotron. It is now routinely produced via the ${ }^{103} \mathrm{Rh}(p, n)$ reaction, though the ${ }^{103} \mathrm{Rh}(d, 2 n)$-process is also interesting (for a recent review on nuclear data $c f$. [21]). Over the last 15 years about 20 cyclotrons have been installed in USA to produce exclusively ${ }^{103} \mathrm{Pd}$, because this radionuclide is commonly used in treatment of prostate cancer, though now with a declining trend.

As far as the radionuclide ${ }^{153} \mathrm{Sm}$ is concerned, production is done at a reactor via the ${ }^{152} \mathrm{Sm}(n, \gamma)$-reaction. Consequently the specific activity is not high. On the other hand, since the cross section for this reaction is relatively high (206 b), the specific activity of ${ }^{153} \mathrm{Sm}$ is not as low as in the case of many other radionuclides produced via the $(n, \gamma)$ reaction.

Regarding the production of the $\alpha$-emitting radionuclide ${ }^{211} \mathrm{At}$, the only reaction utilized so far is the ${ }^{209} \mathrm{Bi}(\alpha, 2 n){ }^{211} \mathrm{At}$ process. A precise control of the energy range is absolutely necessary to avoid the formation of the radioisotope ${ }^{210}$ At which decays to long-lived ${ }^{210} \mathrm{Po}\left(T_{1 / 2}=138.4 \mathrm{~d}\right)$. The methods of chemical separation of radioastatine from the bismuth target have been well worked out [cf. 22]. Other $\alpha$-emitting radionuclides, presently in development, are discussed below.

\section{New developments}

In recent years, development work related to radionuclide production has been carried out mainly in four directions:

- Development of novel positron emitters,

- Development of novel highly ionising radiation emitters for internal radiotherapy,

- Development of novel methodologies for production of some established radionuclides,

- Standardisation of production data.

A brief discussion of those areas is given below.

\subsection{Novel positron emitters}

With the growing significance of PET in diagnostic nuclear medicine, the need for novel positron emitters, also termed as non-standard or innovative positron emitters, has been increasing, especially for studying slower metabolic processes and for quantification of targeted therapy [cf. 23, 24]. Those radionuclides, like the commonly used positron emitters, are also produced exclusively at cyclotrons (or accelerators). The subject has been treated in detail in a recent review [25]. In this article, therefore, only some salient features are discussed.
Table 2. Some novel positron emitters for medical applications. ${ }^{a}$

\begin{tabular}{|c|c|c|c|}
\hline $\begin{array}{l}\text { Radionuclide } \\
\left(T_{1 / 2}\right)\end{array}$ & $\begin{array}{l}\text { Major } \\
\text { production } \\
\text { route }\end{array}$ & $\begin{array}{c}\text { Energy } \\
\text { range } \\
{[\mathrm{MeV}]}\end{array}$ & Application $^{b}$ \\
\hline${ }^{38} \mathrm{~K}(7.6 \mathrm{~min})$ & ${ }^{35} \mathrm{Cl}(\alpha, n)$ & $22 \rightarrow 10$ & Cardiology \\
\hline \multirow[t]{2}{*}{${ }^{55} \mathrm{Co}(17.6 \mathrm{~h})$} & ${ }^{58} \mathrm{Ni}(p, \alpha)$ & $15 \rightarrow 7$ & Tumour imaging; \\
\hline & ${ }^{54} \mathrm{Fe}(d, n)$ & $10 \rightarrow 5$ & neuronal Ca marker \\
\hline${ }^{64} \mathrm{Cu}(12.7 \mathrm{~h})$ & ${ }^{64} \mathrm{Ni}(p, n)$ & $14 \rightarrow 9$ & Radioimmunotherapy \\
\hline${ }^{66} \mathrm{Ga}(9.4 \mathrm{~h})$ & ${ }^{66} \mathrm{Zn}(p, n)$ & $13 \rightarrow 8$ & $\begin{array}{l}\text { Quantification of } \\
\text { SPECT-pharmaceuticals }\end{array}$ \\
\hline${ }^{72} \mathrm{As}(26.0 \mathrm{~h})$ & ${ }^{\text {nat }} \mathrm{Ge}(p, x n)$ & $18 \rightarrow 8$ & $\begin{array}{l}\text { Tumour imaging; } \\
\text { immuno-PET }\end{array}$ \\
\hline${ }^{73} \mathrm{Se}(7.1 \mathrm{~h})$ & ${ }^{75} \mathrm{As}(p, 3 n)$ & $40 \rightarrow 30$ & Selenopharmaceuticals \\
\hline${ }^{76} \mathrm{Br}(16.0 \mathrm{~h})$ & ${ }^{76} \mathrm{Se}(p, n)$ & $15 \rightarrow 8$ & Radioimmunotherapy \\
\hline${ }^{86} \mathrm{Y}(14.7 \mathrm{~h})$ & ${ }^{86} \operatorname{Sr}(p, n)$ & $14 \rightarrow 10$ & Therapy planning \\
\hline${ }^{89} \mathrm{Zr}(78.4 \mathrm{~h})$ & ${ }^{89} \mathrm{Y}(p, n)$ & $14 \rightarrow 10$ & Immuno-PET \\
\hline${ }^{94 m} \mathrm{Tc}(52 \mathrm{~min})$ & ${ }^{94} \operatorname{Mo}(p, n)$ & $13 \rightarrow 8$ & $\begin{array}{l}\text { Quantification of } \\
\text { SPECT-pharmaceuticals }\end{array}$ \\
\hline${ }^{120} \mathrm{I}(1.3 \mathrm{~h})$ & ${ }^{120} \mathrm{Te}(p, n)$ & $13.5 \rightarrow 12$ & Iodopharmaceuticals \\
\hline${ }^{124} \mathrm{I}(4.18 \mathrm{~d})$ & ${ }^{124} \mathrm{Te}(p, n)$ & $12 \rightarrow 8$ & $\begin{array}{l}\text { Tumour targeting; } \\
\text { dosimetry }\end{array}$ \\
\hline
\end{tabular}

a: Produced using a small or medium-sized cyclotron.

b: Each application involves PET imaging.

Most of the novel positron emitters have been developed at laboratories where facilities for the production of standard positron emitters already existed. Some of the very promising non-standard positron emitters are given in Table 2. The common route of production of each radionuclide is the lowenergy $(p, n)$-reaction on an enriched target isotope. In a few cases other low-energy reactions, such as $(d, n)$ and $(p, \alpha)$, have also been employed. For all those radionuclides some sort of novel medical application has been reported. For a few radionuclides, like ${ }^{64} \mathrm{Cu},{ }^{124} \mathrm{I}$ and ${ }^{86} \mathrm{Y}$, a large number of applications have already been demonstrated. The number of relevant reactions studied has therefore also been correspondingly large [cf. 26, 27]. However, the low-energy $(p, n)$-reaction on an enriched target isotope is favoured because it generally leads to a high-purity product.

A typical excitation function of the commonly used $(p, n)$-reaction for the production of a novel positron emitter in the medium mass range is shown in Fig. 1. The threshold lies at about $3 \mathrm{MeV}$ and the maximum at about $10 \mathrm{MeV}$. Thereafter the cross section decreases due to the onset of the competing $(p, 2 n)$-reaction. The optimum energy range for production is thus between 7 and $14 \mathrm{MeV}$. This energy region is within the capacity of a small medical cyclotron and therefore (as mentioned above) most of the development work on novel positron emitters has been done at established PET centres. The $(p, n)$-reaction can be described relatively well by nuclear model calculations and thus, if many data points are available, a theory-based evaluation is possible [28]. Fig. 1 shows, as an example, the data for the excitation function of the ${ }^{64} \mathrm{Ni}(p, n){ }^{64} \mathrm{Cu}$ reaction (for original references $c f$. [28]).

The production of the three more widely used novel positron emitters, viz. ${ }^{64} \mathrm{Cu},{ }^{124} \mathrm{I}$ and ${ }^{86} \mathrm{Y}$, mainly developed at the Research Centre Jülich, is described in some detail below.

The radionuclide ${ }^{64} \mathrm{Cu}$ emits low-energy positrons, has no disturbing $\gamma$-ray, has a suitable half-life and forms in- 


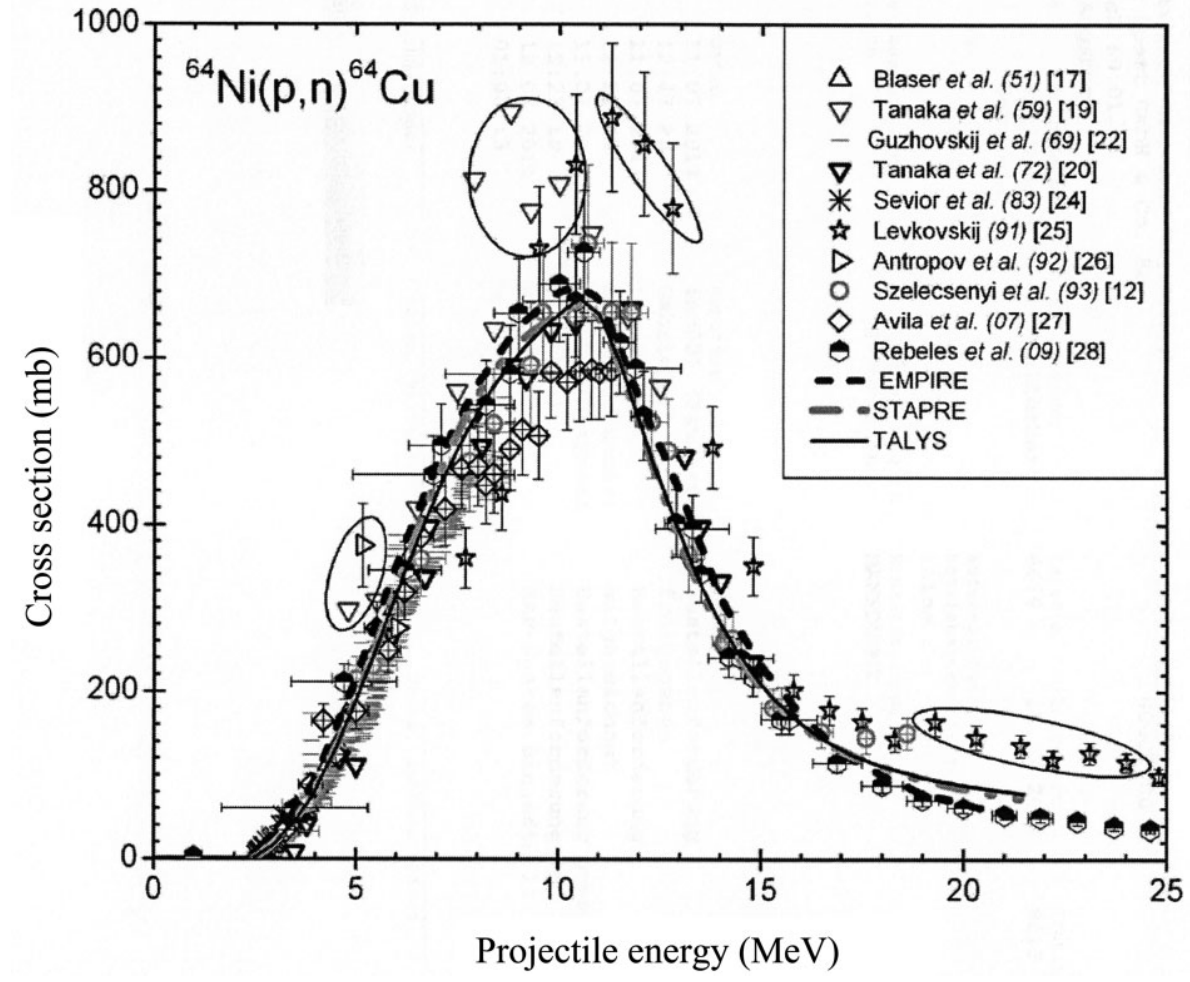

Fig. 1. Experimental data along with the results of nuclear model calculations using the codes EMPIRE, STAPRE and TALYS for the ${ }^{64} \mathrm{Ni}(p, n){ }^{64} \mathrm{Cu}$ reaction. The encircled data were deselected in further evaluation (taken from Ref. [28]). teresting stable co-ordination compounds. It is thus very suitable for studying slow metabolic processes. However, the positron branching is only $17.8 \%$ [29], so that much higher radioactivity has to be injected to achieve a coincidence rate similar to that, for example, with ${ }^{18} \mathrm{~F}$ radiopharmaceuticals. In addition, the remaining $82.2 \%$ decay branching $\left(\beta^{-}, \mathrm{EC}\right)$ induces a non-negligible radiation dose. Due to this reason ${ }^{64} \mathrm{Cu}$ allows a combination of PET with radioimmunotherapy.

The suggested production route ${ }^{64} \mathrm{Ni}(p, n){ }^{64} \mathrm{Cu}[30]$ involves the use of the rather expensive highly enriched target material electroplated on a gold surface. Nonetheless, the technology has been well developed [30-35] for production of ${ }^{64} \mathrm{Cu}$ in batches of about $40 \mathrm{GBq}$ and recovery of the enriched target material. The separation of ${ }^{64} \mathrm{Cu}$ is generally done via anion-exchange chromatography. A recent work [36] describes sophisticated targetry calculations. Due to increasing demand for this radionuclide in radioimmunotherapy, presently a commercialization of this production process is being pursued. However, systematic human use is pending.

In comparison to the ${ }^{64} \mathrm{Ni}(p, n){ }^{64} \mathrm{Cu}$ reaction, for the ${ }^{64} \mathrm{Ni}(d, 2 n){ }^{64} \mathrm{Cu}$ reaction only cross section measurements have been reported. Although the expected yield of ${ }^{64} \mathrm{Cu}$ via the latter reaction is higher, the availability of only lowenergy deuterons at medical cyclotrons has precluded the use of this reaction for production purposes. On the other hand, small amounts of ${ }^{64} \mathrm{Cu}$ have been produced using a deuteron induced reaction on ${ }^{64} \mathrm{Zn}[c f .37,38]$ as well as via an intermediate energy proton induced reaction on enriched ${ }^{68} \mathrm{Zn}$ [ $\left.c f .39\right]$.

The radionuclide ${ }^{124} \mathrm{I}$ is somewhat longer lived $\left(T_{1 / 2}=\right.$ $4.18 \mathrm{~d}$ ) and it has also a relatively low positron branching of $22.0 \%$ [ $f f$. 29]. The radiation dose from this radionuclide is therefore also higher as compared to standard PET radionu- clides. The production route ${ }^{124} \mathrm{Te}(p, n)^{124} \mathrm{I}[c f$. 40] commonly involves irradiation of a ${ }^{124} \mathrm{TeO}_{2}$ target and removal of radioiodine by a distillation process, whereby the irradiated enriched target is regenerated for reuse [ $c f .41-45]$. The use of a ${ }^{124} \mathrm{Te}$-metal target followed by a wet chemical separation of radioiodine has not been very successful. The yield of ${ }^{124} \mathrm{I}$ via the ${ }^{124} \mathrm{Te}(p, n)$-reaction is rather low and the product is somewhat expensive but it is of very high radionuclidic purity [ $c f .27]$. Due to increasing demands for this radionuclide, intensified efforts are underway to produce it in larger quantities.

The production of the radionuclide ${ }^{86} \mathrm{Y}$ is carried out via the ${ }^{86} \mathrm{Sr}(p, n)$-reaction [46] on an enriched ${ }^{86} \mathrm{SrCO}_{3}$ target. The five major separation methods for ${ }^{86} \mathrm{Y}$ involve: (a) coprecipitation with $\mathrm{La}(\mathrm{OH})_{3}$ followed by ion-exchange separation of radioyttrium from bulk lanthanum [47, 48], (b) electrolysis [49-51], (c) multiple column chromatography [52], (d) solvent extraction [53] and (e) simple precipitation of the target element $[54,55]$. Out of those processes, the electrolytic method appears to be more promising. The radionuclide ${ }^{86} \mathrm{Y}$ has become the most suitable positron emitter for quantification of radiation dosimetry of ${ }^{90} \mathrm{Y}$-labelled therapeuticals. Due to the ever increasing demand for this radionuclide, its large scale production is either already established or is being planned at several centres.

Despite the above discussed capability of low-energy nuclear reactions on enriched target isotopes to produce many novel positron emitters, there are some radionuclides which can be obtained only using intermediate energy reactions (for a detailed discussion $c f$. [25]). In particular the production of ${ }^{52} \mathrm{Fe}\left(T_{1 / 2}=8.3 \mathrm{~h}\right),{ }^{73} \mathrm{Se}\left(T_{1 / 2}=7.1 \mathrm{~h}\right),{ }^{77} \mathrm{Kr}$ $\left(T_{1 / 2}=1.2 \mathrm{~h}\right)$ and ${ }^{83} \mathrm{Sr}\left(T_{1 / 2}=32.4 \mathrm{~h}\right)$ by the nuclear reactions ${ }^{55} \mathrm{Mn}(p, 4 n){ }^{52} \mathrm{Fe},{ }^{75} \mathrm{As}(p, 3 n){ }^{73} \mathrm{Se},{ }^{79} \mathrm{Br}(p, 3 n){ }^{77} \mathrm{Kr}$ and ${ }^{85} \mathrm{Rb}(p, 3 n)^{83} \mathrm{Sr}$ demands a high intensity cyclotron, acceler- 
ating protons of energies up to about $70 \mathrm{MeV}$ (in the case of ${ }^{52} \mathrm{Fe}$ preferably up to $100 \mathrm{MeV}$ ).

Although in the intermediate energy range mostly protons are available and are also predominantly used, other charged particles like deuterons, ${ }^{3} \mathrm{He}$ - and $\alpha$-particles may also induce a few useful reactions. For example, intermediate energy deuterons could be useful in the production of ${ }^{64} \mathrm{Cu}$ via the ${ }^{\text {nat }} \mathrm{Zn}(\mathrm{d}, \mathrm{x})$-process, a ${ }^{3} \mathrm{He}$-particle beam in the production of ${ }^{75} \mathrm{Br}$ by the ${ }^{75} \mathrm{As}\left({ }^{3} \mathrm{He}, 3 n\right)$-process and an $\alpha$-particle beam in the production of ${ }^{38} \mathrm{~K}$ and ${ }^{73} \mathrm{Se}$ via the ${ }^{35} \mathrm{Cl}(\alpha, n){ }^{38} \mathrm{~K}$ and ${ }^{70} \mathrm{Ge}(\alpha, n){ }^{73} \mathrm{Se}$ reactions, respectively (for more details $c f$. [25]).

Similar to some commonly used positron emitters made available via generator systems, a few novel and potentially useful positron emitters could also be produced through generators. Some of them are: ${ }^{44} \mathrm{Ti}(60.4 \mathrm{a}) /{ }^{44} \mathrm{Sc}(3.9 \mathrm{~h}),{ }^{52} \mathrm{Fe}$ $(9.1 \mathrm{~h}) /{ }^{52} \mathrm{~m} \mathrm{Mn}(21 \mathrm{~min}),{ }^{62} \mathrm{Zn}(9.1 \mathrm{~h}) /{ }^{62} \mathrm{Cu}(9.7 \mathrm{~min}),{ }^{72} \mathrm{Se}$ $(8.5 \mathrm{~d}) /{ }^{72} \mathrm{As}(26.0 \mathrm{~h}),{ }^{122} \mathrm{Xe}(20.1 \mathrm{~h}) /{ }^{122} \mathrm{I}(3.6 \mathrm{~min})$ and ${ }^{140} \mathrm{Nd}$ (3.4 d) $/{ }^{140} \mathrm{Pr}(3.4 \mathrm{~min})$. The systems ${ }^{52} \mathrm{Fe} /{ }^{52 \mathrm{~m}} \mathrm{Mn},{ }^{62} \mathrm{Zn} /{ }^{62} \mathrm{Cu}$ and ${ }^{122} \mathrm{Xe} /{ }^{122} \mathrm{I}$ were proposed rather long time ago (for more details $c f$. [25]). Out of those, more detailed studies have been carried out only on the system ${ }^{62} \mathrm{Zn} /{ }^{62} \mathrm{Cu}$. In general not much progress has been reported regarding their further applications. The systems ${ }^{72} \mathrm{Se} /{ }^{72} \mathrm{As}[c f .56,57]$ and ${ }^{140} \mathrm{Nd} /{ }^{140} \operatorname{Pr}[c f .58]$ have great potential and deserve more detailed investigations. The generator system ${ }^{44} \mathrm{Ti} /{ }^{44} \mathrm{Sc}$ may also prove to be useful $[c f .59,60]$, though the parent halflife is very long and the cross section of the ${ }^{45} \mathrm{Sc}(p, 2 n)^{44} \mathrm{Ti}$ reaction is rather low [cf. 61]. All of the above mentioned parent radionuclides can be produced only using intermediate energy cyclotrons.

\subsection{Novel therapeutic radionuclides}

\subsubsection{General remarks}

The number of potentially interesting therapeutic radionuclides is very large, especially among the lanthanoids [cf. 62]. However, as mentioned above, in internal radionuclide therapy the emphasis has shifted to low-range but highly ionising radiation emitters. They include low-energy $\beta^{-}$emitters and $\alpha$-particle emitters as well as Auger and conversion electron emitters. Among the $\beta^{-}$emitters, the radionuclides ${ }^{47} \mathrm{Sc}\left(T_{1 / 2}=3.35 \mathrm{~d} ; E_{\beta^{-}}=610 \mathrm{keV}\right),{ }^{67} \mathrm{Cu}$ $\left(T_{1 / 2}=2.58 \mathrm{~d} ; E_{\beta^{-}}=577 \mathrm{keV}\right),{ }^{105} \mathrm{Rh}\left(T_{1 / 2}=1.47 \mathrm{~d} ; E_{\beta^{-}}=\right.$ $560 \mathrm{keV}),{ }^{161} \mathrm{~Tb}\left(T_{1 / 2}=6.90 \mathrm{~d} ; E_{\beta^{-}}=590 \mathrm{keV}\right),{ }^{175} \mathrm{Yb}\left(T_{1 / 2}\right.$ $\left.=4.19 \mathrm{~d} ; E_{\beta^{-}}=466 \mathrm{keV}\right)$ and ${ }^{186} \operatorname{Re}\left(T_{1 / 2}=3.72 \mathrm{~d} ; E_{\beta^{-}}=\right.$ $1070 \mathrm{keV}$ ) have been receiving enhanced attention. Attached to an ideal chemical compound, the therapeutic radionuclide would selectively reach the tumorous cells and cause the therapeutic effect without causing much damage to the healthy surrounding tissue. Some of those radionuclides have been under consideration for a long time, but their production methods have been improving only in recent years, resulting in enhanced interest in novel applications of those radionuclides. A few other $\beta^{-}$emitting radiolanthanides, for example ${ }^{149} \mathrm{Pm}\left(T_{1 / 2}=2.21 \mathrm{~d} ; E_{\beta^{-}}=1060 \mathrm{keV}\right)$ and ${ }^{166} \mathrm{Ho}$ $\left(T_{1 / 2}=1.12 \mathrm{~d} ; E_{\beta^{-}}=1860 \mathrm{keV}\right)$ are also of potential interest for preparing tumour seeking agents.

Concerning targeted $\alpha$-particle therapy, presently there is great interest in ${ }^{225} \mathrm{Ac}\left(T_{1 / 2}=10.0 \mathrm{~d} ; E_{\alpha}=5830 \mathrm{keV}\right)$ which is useful in itself as well as for providing ${ }^{213} \mathrm{Bi}\left(T_{1 / 2}=\right.$ $46 \mathrm{~min} ; E_{\alpha}=5900 \mathrm{keV}$ ) through a generator system. In recent years some interest has also developed in ${ }^{226} \mathrm{Th}\left(T_{1 / 2}=\right.$ $31 \mathrm{~min} ; E_{\alpha}=6340 \mathrm{keV}$ ) which can be obtained through a generator column loaded with ${ }^{230} \mathrm{U}\left(T_{1 / 2}=20.8 \mathrm{~d} ; E_{\alpha}=\right.$ $5890 \mathrm{keV})$. A few other potentially useful $\alpha$-emitters are ${ }^{149} \mathrm{~Tb}\left(T_{1 / 2}=4.1 \mathrm{~h} ; E_{\alpha}=3970 \mathrm{keV}\right),{ }^{223} \mathrm{Ra}\left(T_{1 / 2}=11.43 \mathrm{~d}\right.$; $\left.E_{\alpha}=5720 \mathrm{keV}\right)$ and ${ }^{224} \mathrm{Ra}\left(T_{1 / 2}=3.66 \mathrm{~d} ; E_{\alpha}=5683 \mathrm{keV}\right)$.

As far as novel Auger electron, conversion electron and $\mathrm{X}$-ray emitters are concerned, it should be mentioned that the radionuclides ${ }^{67} \mathrm{Ga}\left(T_{1 / 2}=3.26 \mathrm{~d}\right)$ and ${ }^{111} \mathrm{In}\left(T_{1 / 2}=\right.$ $2.8 \mathrm{~d}$ ), previously used as SPECT radionuclides, are now also being considered for application in Auger therapy. Other potentially interesting radionuclides are ${ }^{117 \mathrm{~m}} \mathrm{Sn}\left(T_{1 / 2}=\right.$ $13.6 \mathrm{~d}$, conversion electrons $),{ }^{131} \mathrm{Cs}\left(\left(T_{1 / 2}=9.7 \mathrm{~d}\right.\right.$; X-rays $)$, ${ }^{140} \mathrm{Nd}\left(T_{1 / 2}=3.37 \mathrm{~d}\right.$; Auger electrons $),{ }^{193 \mathrm{~m}} \mathrm{Pt}\left(T_{1 / 2}=4.33 \mathrm{~d}\right.$; Auger electrons) and ${ }^{195 \mathrm{~m}} \mathrm{Pt}\left(T_{1 / 2}=4.02 \mathrm{~d}\right.$; Auger electrons $)$.

\subsubsection{Novel low-energy $\beta^{-}$emitters}

The production of the six low-energy $\beta^{-}$emitting radionuclides mentioned above, viz. ${ }^{47} \mathrm{Sc},{ }^{67} \mathrm{Cu},{ }^{105} \mathrm{Rh},{ }^{161} \mathrm{~Tb},{ }^{175} \mathrm{Yb}$ and ${ }^{186} \mathrm{Re}$, was started using a nuclear reactor, and in the case of ${ }^{47} \mathrm{Sc},{ }^{105} \mathrm{Rh}$ and ${ }^{161} \mathrm{~Tb}$ it is still done at reactors, although following modified routes to achieve higher specific activity. The radionuclide ${ }^{47} \mathrm{Sc}$ is produced either via the $\left.{ }^{46} \mathrm{Ca}(n, \gamma)\right)^{47} \mathrm{Ca} \stackrel{\beta^{-}}{\longrightarrow}{ }^{47} \mathrm{Sc}$ process or through the ${ }^{47} \mathrm{Ti}(n, p){ }^{47} \mathrm{Sc}$ reaction. In both cases a highly enriched target is needed. The production via the ${ }^{47} \mathrm{Ti}(n, p){ }^{47} \mathrm{Sc}$ reaction is more economical and the radionuclide has been produced in quantities sufficient for applications, though only using the high flux reactor at BNL $[c f .63,64]$. For the production of ${ }^{105} \mathrm{Rh}$, the process ${ }^{104} \mathrm{Ru}(n, \gamma){ }^{105} \mathrm{Ru} \stackrel{\beta^{-}}{\longrightarrow}{ }^{105} \mathrm{Rh}$ is utilized $\left[c f\right.$. 65]. The radionuclide ${ }^{161} \mathrm{~Tb}$ is produced through the process ${ }^{160} \mathrm{Gd}(n, \gamma)^{161} \mathrm{Gd} \stackrel{\beta^{-}}{\longrightarrow}{ }^{161} \mathrm{~Tb}[c f .62]$. In the case of ${ }^{175} \mathrm{Yb}$, production is still done using the ${ }^{174} \mathrm{Yb}(n, \gamma)$ reaction, since the possible route ${ }^{175} \mathrm{Lu}(n, p){ }^{175} \mathrm{Yb}$, expected to give a higher specific activity product, has so far not been developed.

In contrast to ${ }^{47} \mathrm{Sc},{ }^{105} \mathrm{Rh},{ }^{161} \mathrm{~Tb}$ and ${ }^{175} \mathrm{Yb}$, the production of the radionuclides ${ }^{67} \mathrm{Cu}$ and ${ }^{186} \mathrm{Re}$ is shifting over to cyclotrons. The quality and quantity of ${ }^{67} \mathrm{Cu}$ produced by the ${ }^{67} \mathrm{Zn}(n, p){ }^{67} \mathrm{Cu}$ reaction in a nuclear reactor do not meet the specifications required for its use in radioimmunotherapy due to many active and inactive impurities. Its production has been investigated at a small cyclotron $\left(E_{\mathrm{p}}=18 \rightarrow\right.$ $12 \mathrm{MeV})$ through the reaction ${ }^{70} \mathrm{Zn}(p, \alpha){ }^{67} \mathrm{Cu}$ on an enriched target [cf. 66]. The yield is, however, low. More promising is the ${ }^{68} \mathrm{Zn}(p, 2 p){ }^{67} \mathrm{Cu}$ reaction using high-energy protons. This route was applied earlier $[c f .67,68]$. However, since ${ }^{\text {nat }} \mathrm{Zn}$ was used as target material, the specific activity achieved was rather low for radioimmunotherapeutic applications due to the formation of stable ${ }^{63,65} \mathrm{Cu}[c f .64]$. Some recent radiochemical measurements [cf. 69] show that a highly enriched ${ }^{6} \mathrm{Zn}$ target and the energy range $E_{\mathrm{p}}=70 \rightarrow 30 \mathrm{MeV}$ lead to ${ }^{67} \mathrm{Cu}$ of high quality. A comparison of the ${ }^{67} \mathrm{Cu}$ yields calculated from the excitation functions of the two production reactions developed at cyclotrons, namely ${ }^{70} \mathrm{Zn}(p, \alpha){ }^{67} \mathrm{Cu}$ and ${ }^{68} \mathrm{Zn}(p, 2 p){ }^{67} \mathrm{Cu}$, is given in Fig. 2. Evidently the latter reaction is more suitable, 


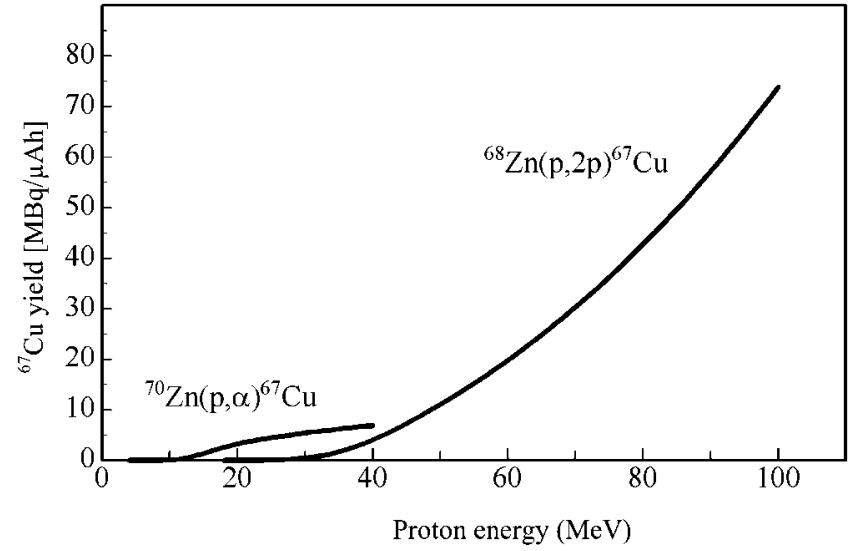

Fig. 2. Integral yields of ${ }^{67} \mathrm{Cu}$ in proton-induced production reactions on highly enriched target isotopes ${ }^{68} \mathrm{Zn}$ and ${ }^{70} \mathrm{Zn}$, shown as a function of proton energy (curves are based on the numerical values given in Ref. [117]).

but it demands an intermediate energy cyclotron. In view of the great therapeutic potential of this radionuclide, considerable efforts are underway in several laboratories to produce it efficiently, mainly via the ${ }^{68} \mathrm{Zn}(p, 2 p){ }^{67} \mathrm{Cu}$ process, i.e. using about $70 \mathrm{MeV}$ protons.

Very recently the reaction ${ }^{70} \mathrm{Zn}(d, \alpha n){ }^{67} \mathrm{Cu}$ on highly enriched ${ }^{70} \mathrm{Zn}$ has also been investigated over the deuteron energy range of 10 to $20 \mathrm{MeV}$ [70]. The reaction cross sections and the ${ }^{67} \mathrm{Cu}$ yield are about $50 \%$ higher than those for the ${ }^{70} \mathrm{Zn}(p, \alpha){ }^{67} \mathrm{Cu}$ reaction. However, the rare availability of high-intensity $20 \mathrm{MeV}$ deuteron beam and the high cost of the enriched target material may be restrictive factors in the use of this reaction for production purposes.

With regard to the production of ${ }^{186} \mathrm{Re}$, the original ${ }^{185} \operatorname{Re}(n, \gamma){ }^{186} \operatorname{Re}$ reaction has been dropped due to the resulting low specific activity. The new method of preparation of this radionuclide is the ${ }^{186} \mathrm{~W}(p, n){ }^{186} \mathrm{Re}$ reaction, though the ${ }^{186} \mathrm{~W}(d, 2 n){ }^{186} \mathrm{Re}$ reaction has also been investigated and gives higher yield than the $(p, n)$ reaction. Most of the studies deal with nuclear reaction cross-section measurements [for a review $c f$. 71]. Only in three works [72-74] small scale production has also been reported. A recent critical analysis [71] showed that, for obtaining a high-purity product, an enriched ${ }^{186} \mathrm{~W}$ target is absolutely necessary and the maximum proton energy used should not exceed $18 \mathrm{MeV}$. The formation of the very long-lived isomer, ${ }^{186 \mathrm{~m}} \mathrm{Re}\left(T_{1 / 2}=\right.$ $2 \times 10^{5}$ a) also needs special consideration in both $(p, n)$ and $(d, 2 n)$ reactions. Presently, efforts are underway in a few laboratories to produce this radionuclide in larger quantities, without which its availability will remain limited.

Research and development work on the production of many other potentially useful $\beta^{-}$emitting radionuclides, especially lanthanoids, is also going on. This involves mainly nuclear reaction cross-section measurements using charged particles and development of chemical separations for reactor neutron irradiated targets.

\subsubsection{Novel $\alpha$-emitters}

Extensive effort is presently being invested in the development of ${ }^{225} \mathrm{Ac}$. On one hand its separation from nuclear waste $\left({ }^{229} \mathrm{Th}\right)$ is being optimised and, on the other, the
${ }^{226} \mathrm{Ra}(p, 2 n){ }^{225} \mathrm{Ac}$ reaction, making use of the radioactive target material ${ }^{226} \mathrm{Ra}$, is being developed [ $c f$. 75]. A third possibility under investigation is its production via irradiation of ${ }^{232} \mathrm{Th}$ with intermediate energy protons [76,77]. In the latter case, however, strong chemical effort is involved to separate the desired radionuclide from the fission products.

The $\alpha$-emitting radionuclide ${ }^{223} \mathrm{Ra}$ holds great promise for bone cancer therapy [78]. It was obtained via the chain ${ }^{226} \operatorname{Ra}(n, \gamma){ }^{227} \mathrm{Ra}(42.2 \mathrm{~min}) \stackrel{\beta^{-}}{\longrightarrow}{ }^{227} \mathrm{Ac}(21.77 \mathrm{a}) \stackrel{\beta^{-}}{\longrightarrow}{ }^{223} \mathrm{Ra}$. Another potentially interesting production route entails the irradiation of ${ }^{232} \mathrm{Th}$ with intermediate energy protons [cf. 76].

The production of ${ }^{230} \mathrm{U}$ (and its daughter ${ }^{226} \mathrm{Th}$ ) has been studied by ${ }^{231} \mathrm{~Pa}(p, 2 n){ }^{230} \mathrm{U},{ }^{231} \mathrm{~Pa}(d, 3 n){ }^{230} \mathrm{U}$ and ${ }^{232} \mathrm{Th}(p, 3 n)^{230} \mathrm{~Pa} \stackrel{\beta^{-}}{\longrightarrow}{ }^{230} \mathrm{U}$ processes [79-81]. The target material ${ }^{231} \mathrm{~Pa}$ is radioactive; the chemical separation involved is thus very demanding [79]. There appears to be some potential for therapeutic application of this radionuclide.

The radionuclide ${ }^{149} \mathrm{~Tb}$ is a rather exotic but an interesting $\alpha$-emitter, particularly because of its low $\alpha$-particle energy of about $4 \mathrm{MeV}$. It has been produced to date by two high-energy processes, namely ${ }^{\text {nat }} \mathrm{Gd}(p, x n)^{149} \mathrm{~Tb}$ (at $E_{\mathrm{p}}>$ $100 \mathrm{MeV}$ ) and ${ }^{165} \mathrm{Ho}\left(p\right.$, spall ${ }^{149} \mathrm{~Tb}$ (at $\left.E_{\mathrm{p}}>200 \mathrm{MeV}\right)$, as well as by the heavy-ion induced reaction ${ }^{141} \operatorname{Pr}\left({ }^{12} \mathrm{C}, 4 n\right){ }^{149} \mathrm{~Tb}$. Further development work will depend on the demonstrated therapeutic utility of this radionuclide.

\subsubsection{Novel Auger electron emitters}

The production of the radionuclides ${ }^{67} \mathrm{Ga}$ and ${ }^{111} \mathrm{In}$, used previously for SPECT studies and now being considered for Auger electron therapy, is well established (see above). In both cases the $(p, 2 n)$-reaction on an enriched target is used [cf. 4]. The same is true for ${ }^{77} \mathrm{Br}\left(T_{1 / 2}=57.0 \mathrm{~h}\right)$. It was previously regarded as a SPECT nuclide but is now being considered more for Auger therapy. Regarding the potentially interesting Auger electron emitters ${ }^{131} \mathrm{Cs},{ }^{140} \mathrm{Nd}$, ${ }^{165} \mathrm{Er},{ }^{169} \mathrm{Yb}$, ${ }^{193 \mathrm{~m}} \mathrm{Pt}$ and ${ }^{195 \mathrm{~m}} \mathrm{Pt}$, various production methods are under investigation. The radionuclides ${ }^{165} \mathrm{Er}$ and ${ }^{169} \mathrm{Yb}$ are produced by the $(n, \gamma)$-reaction which again results in low specific activity. Several charged particle induced reactions have been investigated for their production in nocarrier-added form. However, both the radionuclides appear to be unsuitable for open source therapy: the half-life of ${ }^{165} \mathrm{Er}$ is too short and that of ${ }^{169} \mathrm{Yb}$ rather long. ${ }^{169} \mathrm{Yb}$ is being considered for brachytherapy, possibly as a substitute for ${ }^{192} \mathrm{Ir}$. But for that purpose the reactor production of ${ }^{169} \mathrm{Yb}$ appears to be adequate. The radionuclide ${ }^{131} \mathrm{Cs}$, on the other hand, is of considerable promise for prostate cancer brachytherapy and it may compete with the wellestablished radionuclide ${ }^{103} \mathrm{Pd}$ mentioned above. Its effective production through the ${ }^{131} \mathrm{Xe}(p, n){ }^{131} \mathrm{Cs}$ reaction has been demonstrated [ $c f$. 82]. The radionuclide ${ }^{140} \mathrm{Nd}$ is interesting, not only because of its therapeutic effect but also because of its positron-emitting short-lived daughter nuclide ${ }^{140} \mathrm{Pr}$ which allows its localisation via $\mathrm{PET}$ imaging. Its production is carried out either by the ${ }^{\text {nat }} \mathrm{Ce}\left({ }^{3} \mathrm{He}, x n\right){ }^{140} \mathrm{Nd}$ process or through the ${ }^{141} \operatorname{Pr}(p, 2 n)^{140} \mathrm{Nd}$ reaction [ $c f$. 83].

The radionuclides ${ }^{193 \mathrm{~m}} \mathrm{Pt}$ and ${ }^{195 \mathrm{~m}} \mathrm{Pt}$ are pure X-ray and Auger electron emitters, each decay leading to more than 


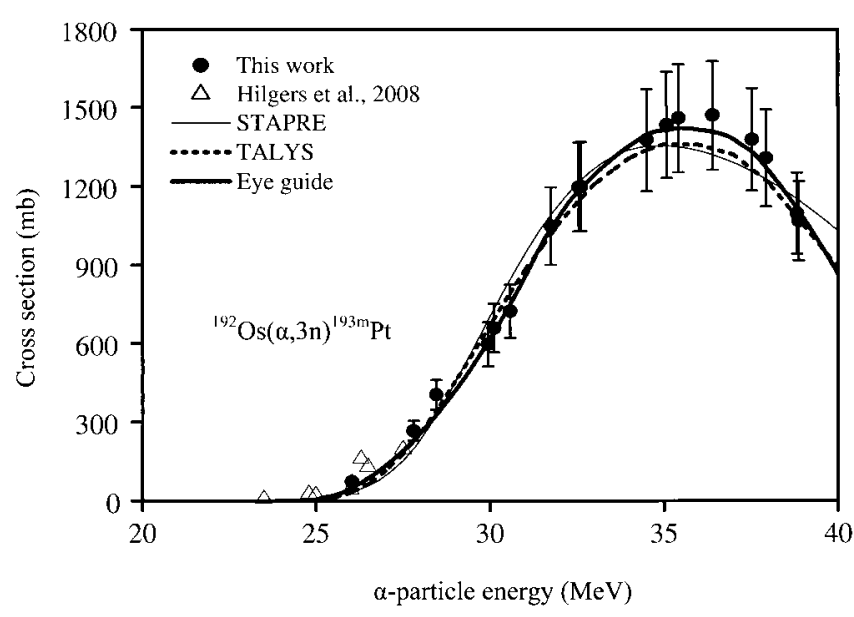

Fig. 3. Experimentally determined and theoretically calculated cross section data for the ${ }^{192} \mathrm{Os}(\alpha, 3 n){ }^{193 \mathrm{~m}} \mathrm{Pt}$ reaction, shown as a function of the $\alpha$-particle energy. The model calculations were done using the codes TALYS and STAPRE (taken from Ref. [85]).

30 secondary electrons. Furthermore, platinum-complexes (like cis-di-chlorodiaminplatinum) have been in use in chemotherapy as potent antitumour agents for a long time. Thus both those radionuclides have great potential in Auger electron therapy. So far the major drawback in their widespread use has been their non-availability with a high specific activity. In a recent study it could be shown that small amounts of ${ }^{195 \mathrm{~m}} \mathrm{Pt}$ could be produced with high specific activity via the ${ }^{192} \operatorname{Os}(\alpha, n){ }^{195 \mathrm{~m}} \mathrm{Pt}$ reaction [84]. Using the same target but higher energy $\alpha$-particles, on the other hand, it was found that ${ }^{193 \mathrm{~m}} \mathrm{Pt}$ of high specific activity could be advantageously produced through the ${ }^{192} \operatorname{Os}(\alpha, 3 n){ }^{193 \mathrm{~m}} \mathrm{Pt}$ reaction [85]. The excitation function of this reaction is shown in Fig. 3. It is reproduced very well by nuclear model calculations. Over the optimum energy range $E_{\alpha}=40 \rightarrow 30 \mathrm{MeV}$, ${ }^{193 \mathrm{~m}} \mathrm{Pt}$ theoretical yield amounts to about $10 \mathrm{MBq} / \mu \mathrm{Ah}$. Thus this radionuclide can be produced in quantities sufficient for therapeutic applications. This has already been practically demonstrated [86].

\subsection{Novel methodologies for production of some established radionuclides}

There may be several motivations behind the search for novel methodologies for production of some established radionuclides, e.g., to

- increase the yield, radionuclidic purity or specific activity of the desired product,

- produce the daughter nuclide directly, if the parent of a generator system is not easily available,

- achieve more security in the supply of the radionuclide due to technical constraints regarding irradiation facility.

The first motivation has been amply discussed above. The shifts in the production of ${ }^{64} \mathrm{Cu},{ }^{67} \mathrm{Cu},{ }^{103} \mathrm{Pd},{ }^{186} \mathrm{Re}$ and ${ }^{193 \mathrm{~m}} \mathrm{Pt}$ from reactor to cyclotron serve here as very good examples. Charged-particle induced reactions generally give products of higher specific activity. In some cases, however, even an alternative route does not serve the purpose. For production of ${ }^{153} \mathrm{Sm},{ }^{159} \mathrm{Gd},{ }^{169} \mathrm{Er},{ }^{192} \mathrm{Ir}$ and several other radionuclides in the group of lanthanoids, for example, exten- sive charged-particle induced reaction cross-section measurements have been performed at Brussels, Debrecen and Jülich, but no suitable alternative route has been found to replace the $(n, \gamma)$-reaction and thus increase the specific activity of the desired product. Only in the case of ${ }^{153} \mathrm{Sm}$, the ${ }^{150} \mathrm{Nd}(\alpha, n)$-reaction on a highly enriched target bears some promise [ $c f .87]$ to provide a high specific activity product. The cost would, however, be rather high.

In recent years considerable methodological development has followed also on some known generators to improve their performance (e.g. minimisation of breakthrough, improvement in elution yield, concentration of the eluate, etc.). Of particular interest in this respect is the ${ }^{68} \mathrm{Ge} /{ }^{68} \mathrm{Ga}$ system where extensive work has led to a very efficient processing of the ${ }^{68} \mathrm{Ga}$-eluate for medical application $[c f .88,89]$. In view of the increasing importance of ${ }^{68} \mathrm{Ga}$ in labelling molecules for PET studies [ $c f$. 90-93] this methodology holds great promise.

Under the second motivation, attempts related to "inhouse" direct production of two generator products, namely ${ }^{62} \mathrm{Cu}\left(T_{1 / 2}=10 \mathrm{~min}\right)$ and ${ }^{68} \mathrm{Ga}\left(T_{1 / 2}=1.13 \mathrm{~h}\right)$, may be mentioned. The ${ }^{62} \mathrm{Zn} /{ }^{62} \mathrm{Cu}$ generator demands frequent production of the parent ${ }^{62} \mathrm{Zn}$ at a $30 \mathrm{MeV}$ cyclotron because it is rather short-lived $\left(T_{1 / 2}=9.13 \mathrm{~h}\right)$. It was therefore thought worthwhile to produce ${ }^{62} \mathrm{Cu}$ directly through the ${ }^{62} \mathrm{Ni}(p, n)$-reaction on an enriched target at a small-sized cyclotron [94] or via the ${ }^{59} \operatorname{Co}(\alpha, n)$-reaction on a natural target at a medium-sized cyclotron [95]. Those procedures have, however, not found much practical application because of the short half-life of ${ }^{62} \mathrm{Cu}$. Regarding the second system, viz. ${ }^{68} \mathrm{Ge} /{ }^{68} \mathrm{Ga}$ generator, though commercially developed, the availability is rather limited. In view of the ever enhancing importance of ${ }^{68} \mathrm{Ga}$, the notion is developing to produce this radionuclide directly through the ${ }^{68} \mathrm{Zn}(p, n)$-reaction on an enriched target at a small-sized cyclotron or via the ${ }^{65} \mathrm{Cu}(\alpha, n)$-reaction on ${ }^{\text {nat }} \mathrm{Cu}$ at a medium-sized cyclotron (for more discussion $c f$. [96]). The prospects for direct production of this radionuclide appear to be favourable, though the effort involved will be much more than in the generator elution.

The most conspicuous and important example under the third motivation is that of ${ }^{99 \mathrm{~m}} \mathrm{Tc}$. As discussed above, the supply of this commonly used diagnostic radionuclide is rather jeopardized due to increasing uncertainty in the availability of the fission produced ${ }^{99}$ Mo for preparing a generator system. An intense search for alternative routes of production of ${ }^{99} \mathrm{Mo}$ and ${ }^{99 \mathrm{~m}} \mathrm{Tc}$ is therefore imminent. This topic is therefore discussed in more detail.

\subsubsection{Alternative routes of production of ${ }^{99} \mathrm{Mo}$ and ${ }^{99 \mathrm{~m}} \mathrm{Tc}$}

The suggested routes which are not dependent on a nuclear reactor are given below:
(a) ${ }^{\text {nat }} \mathrm{U}(\gamma, f)^{99} \mathrm{Mo}$;
(b) ${ }^{232} \mathrm{Th}(p, f)^{99} \mathrm{Mo}$;
(c) ${ }^{100} \operatorname{Mo}(\gamma, n){ }^{99} \mathrm{Mo}$;
(d) ${ }^{100} \mathrm{Mo}(n, 2 n){ }^{99} \mathrm{Mo}$;
(e) $\left.{ }^{100} \mathrm{Mo}(p, d+p n)\right)^{99} \mathrm{Mo}$; (f) ${ }^{100} \mathrm{Mo}(d, t+p 2 n){ }^{99} \mathrm{Mo}$;
(g) ${ }^{100} \mathrm{Mo}(p, 2 n){ }^{99 \mathrm{~m}} \mathrm{Tc}$;
(h) ${ }^{100} \mathrm{Mo}(d, 3 n)^{99 \mathrm{~m}} \mathrm{Tc}$.

It has been suggested [97] that high-energy photons produced at accelerators could be used for production of ${ }^{99} \mathrm{Mo}$ 
via photofission of nat $U$. This would lead to high specific activity ${ }^{99} \mathrm{Mo}$, but due to the low photofission cross section of ${ }^{\text {nat }} U(160 \mathrm{mb})$, the yield of ${ }^{99}$ Mo would be by a factor of about $3.5 \times 10^{3}$ lower than that in the neutron induced fission of ${ }^{235} \mathrm{U}$. The yield could be increased by developing a high power accelerator, but this has yet to be demonstrated.

The cross section for the formation of ${ }^{99} \mathrm{Mo}$ in the fission of ${ }^{232} \mathrm{Th}$ with $22 \mathrm{MeV}$ protons is about $34 \mathrm{mb}$ [98]. Recently, Abbas et al. [99] performed a feasibility study and showed that with $40 \mathrm{MeV}$ protons about $50 \mathrm{GBq}$ of ${ }^{99} \mathrm{Mo}$ could be produced. This is a potentially useful reaction, provided a high-current accelerator is made available and an effective procedure for the radiochemical separation of ${ }^{99} \mathrm{Mo}$ is worked out. The expected yields, however, suggest that this procedure could meet the regional demands but not international needs.

The cross section of the ${ }^{100} \operatorname{Mo}(\gamma, n)^{99}$ Mo reaction is also small $(150 \mathrm{mb}$ at the maximum of the peak at $14 \mathrm{MeV})$ [cf. 100]. A study on the ${ }^{100} \operatorname{Mo}(n, 2 n)^{99}$ Mo process [ $c f$. 101] claims that amounts of ${ }^{99}$ Mo comparable to those produced through the ${ }^{98} \mathrm{Mo}(n, \gamma){ }^{99} \mathrm{Mo}$ reaction in a low flux reactor could be obtained, provided a proper accelerator for $14 \mathrm{MeV}$ neutron production (through the $d, t$ reaction) is developed. The technical difficulties to be overcome are enormous; furthermore, the drawbacks of the ${ }^{99} \mathrm{Mo}$ produced with large amount of the inactive carrier will remain (see discussion above). More attention is therefore presently focused on production of ${ }^{99} \mathrm{Mo}$ and ${ }^{99 \mathrm{~m}} \mathrm{Tc}$ using charged-particle induced reactions on ${ }^{100} \mathrm{Mo}$.

The possibility of production of ${ }^{99} \mathrm{Mo}$ through the ${ }^{100} \mathrm{Mo}(p, d+p n){ }^{99} \mathrm{Mo}$ reaction was investigated under an IAEA-sponsored project, utilizing highly enriched ${ }^{100} \mathrm{Mo}$ target [cf. 102]; due to low cross section it was found to be unsuitable. Although $\mathrm{GBq}$ amounts of ${ }^{99} \mathrm{Mo}$ could be produced using long irradiations of thick targets covering the energy range $E_{\mathrm{p}}=65 \rightarrow 10 \mathrm{MeV}$, the preparation of the generator and, above all, the recovery of the expensive enriched material would pose great technological and handling problems. Furthermore, the product would not be carrier-free. Although subsequent measurements and evaluations [ $c f$. 103-106] showed slightly higher cross sections, the basic conclusion given in [102] did not change. The ${ }^{100} \mathrm{Mo}(d, t+p 2 n){ }^{99} \mathrm{Mo}$ reaction has a threshold of about $20 \mathrm{MeV}$ and the cross section is lower than for the proton induced reaction [ $c f .107-109]$. Furthermore, in this case also the problem of carrier will remain. It is therefore concluded that this reaction is also not suitable for routine production of ${ }^{99} \mathrm{Mo}$, being even less favourable than the ${ }^{100} \operatorname{Mo}(p, d+p n)$ reaction.

It was also concluded that the direct route of production of ${ }^{99 \mathrm{~m}} \mathrm{Tc}$ via the ${ }^{100} \mathrm{Mo}(p, 2 n)^{99 \mathrm{~m}} \mathrm{Tc}$ reaction at a cyclotron using $22 \mathrm{MeV}$ protons on the target is worth considering for local production and consumption [102]. The corresponding ${ }^{100} \mathrm{Mo}(d, 3 n)^{99 \mathrm{~m}} \mathrm{Tc}$ reaction with $25 \mathrm{MeV}$ deuterons would give a slightly higher yield of ${ }^{99 \mathrm{~m}} \mathrm{Tc}$ [107-109], but as deuterons of that energy are rarely available with high intensities, the method is presently not of much interest. As regards the ${ }^{100} \mathrm{Mo}(p, 2 n)^{99 \mathrm{~m}} \mathrm{Tc}$ reaction, recently some more accurate cross section measurements have been done [104106] and its practical application was demonstrated first by Guérin et al. [110] and later by Morley et al. [111]. The quality of cyclotron-produced ${ }^{99 \mathrm{~m}} \mathrm{Tc}$ with regard to radiopharmaceutical production was found to be similar to that obtained via the ${ }^{99} \mathrm{Mo} /{ }^{99 \mathrm{~m}} \mathrm{Tc}$ generator system.

However, the effect of the long-lived impurities $\left({ }^{97 \mathrm{~g}} \mathrm{Tc}\right.$, ${ }^{98} \mathrm{Tc},{ }^{99 \mathrm{~g}} \mathrm{Tc}$; all with $T_{1 / 2}>10^{5} \mathrm{a}$ ) on the ${ }^{99 \mathrm{~m}} \mathrm{Tc}$ specific activity has still to be investigated [cf. 112], as well as the achievable radionuclidic purity as a function of the isotopic composition of the enriched ${ }^{100}$ Mo target [ $\left.c f .112,113\right]$. In fact they may both become the deciding factors in the use of the cyclotron-produced ${ }^{99 \mathrm{~m}} \mathrm{Tc}$.

A critical analysis of the ${ }^{100} \operatorname{Mo}(p, 2 n)^{99 \mathrm{~m}} \mathrm{Tc}$ route for the production of ${ }^{99 \mathrm{~m}} \mathrm{Tc}$ at a cyclotron suggests that four basic requirements will have to be fulfilled to make this method effective:

1. Use of highly enriched ${ }^{100}$ Mo target, including efficient recycling,

2. Radiochemical separation immediately after irradiation,

3. Daily production schedule,

4. Good logistics.

The target enrichment is crucial. If it is of low enrichment, several radionuclidic impurities $\left({ }^{95 \mathrm{~m}} \mathrm{Tc},{ }^{96 \mathrm{~m}} \mathrm{Tc}\right.$, etc.) will occur as it has been shown in recent studies $[c f .112$, 113]. The radiochemical separation of ${ }^{99 \mathrm{~m}} \mathrm{Tc}$ from a ${ }^{100} \mathrm{MoO}_{3}$ target could be performed via thermochromatography, as it was done in the case of ${ }^{94 \mathrm{~m}} \mathrm{Tc}$ from a ${ }^{94} \mathrm{MoO}_{3}$ target [114]. Alternatively, a wet chemical method using ion-exchange chromatography could be used $[c f .110,115]$. An important aspect is also the recovery of the enriched target material. Finally, due to its short half-life, the production of ${ }^{99 \mathrm{~m}} \mathrm{Tc}$ will have to be done on a regular (daily) basis, and the supply of various nearby laboratories would need good logistics.

The on-going development work will certainly lead to sufficient quantities of ${ }^{99 \mathrm{~m}} \mathrm{Tc}$ for local or regional use, provided the level of the ${ }^{99 \mathrm{~g}} \mathrm{Tc}$ impurity is comparable to that in the generator produced ${ }^{99 \mathrm{~m}} \mathrm{Tc}$. However, this author is convinced that it is illusory to expect that the cyclotron production of ${ }^{99 \mathrm{~m}} \mathrm{Tc}$ will solve the world shortage problem. For large scale production and supply to all parts of the world, the utilization of the ${ }^{235} \mathrm{U}(n, f)$-process will remain a necessity, though intensive efforts need to be invested to shift the process from high enrichment uranium (HEU) target to low enrichment uranium (LEU) target.

\subsection{Standardisation of production data}

As described above, presently extensive research and development work on various aspects of production of medical radionuclides is going on in many of laboratories. It is therefore imperative that some sort of evaluation of the reported information is done to standardise the data and procedures to be able to assist the user in production of medical radionuclides of acceptable quality.

As regards commonly used reactor radionuclides, extensive neutron-induced reaction cross section data are available in several evaluated nuclear data files (e.g. ENDF/BVII), thanks to energy-related reactor programmes, and an excellent manual [2] has been prepared concerning other production details of those radionuclides.

For accelerator-based radionuclides, whereas vast information is available, particularly on targetry and chemical 
separation procedures, no authentic standardisation work has been reported. The main reason is that each laboratory uses a methodology suitable to its own cyclotron and radiochemistry facility. As regards nuclear data for production, however, the situation is better and is discussed below.

All charged-particle induced reaction cross section data are promptly compiled in the EXFOR file coordinated by the IAEA. For potentially interesting production reactions, generally a large number of measurements are available in the literature. It appeared therefore incumbent to devote some effort to the evaluation of those data. The IAEA embarked on this mission about 15 years ago and organised two successive co-ordinated research programmes (CRPs) in which about a dozen laboratories participated, under guidance of the Research Centre Jülich. Since no evaluation methodology existed for charged-particle induced reactions, the initial work was rather empirical. However, in later years strong application of nuclear models could be built in. The evaluated and recommended data for the major diagnostic radionuclides are now available in [116] and those for the therapeutic radionuclides in [117]. They should allow a proper selection of the projectile energy range in a target to ensure high radionuclidic purity of the desired product. In addition, the exact yields of the desired radionuclide and the accompanying radioactive impurities can be accurately calculated. A few groups are now also individually engaged in this type of work [cf. 21, 118].

Further work on the validation of evaluated data as well as on the evaluation of data for other emerging radionuclides is necessary.

\section{Future directions and perspectives}

Radioactivity has revolutionized medicine. The radionuclide production technology is well developed and several suitable radiopharmaceuticals are now widely available for patient care, both with respect to diagnosis and radiotherapy. The future prospects of the tracer technology look bright. However, innovative notions and approaches will need to be followed to keep pace with other medical imaging diagnostic and therapeutic techniques. The emerging problems will demand enhanced attention in the following directions.

\subsection{Patient care programme}

With regard to the apprehension about the secure supply of the most commonly used diagnostic radionuclide ${ }^{99 \mathrm{~m}} \mathrm{Tc}$, presently produced by fission of highly enriched ${ }^{235} \mathrm{U}$, it is likely that the industry would modify the industrial production process to be able to cope with the use of low-enriched ${ }^{235} \mathrm{U}$ (thereby reducing the danger of nuclear weapons' proliferation). The dependence on nuclear reactors will, however, remain. If at the same time some countries in the OECD-area may decide to utilize a few modern research reactors for production of fission ${ }^{99} \mathrm{Mo}$, the situation may improve. At least one initiative to make use of the München reactor for this purpose appears promising. Furthermore, if a few new powerful research reactors could be constructed in countries with fast developing economies and technologies, e.g. China, the problem could be solved. On the other hand, if no progress is made in the above mentioned three directions, several scenarios may emerge, e.g.

1. Cyclotron production of ${ }^{99 \mathrm{~m}} \mathrm{Tc}$. As mentioned above, the question of short- and long-lived impurities needs urgently to be solved. Furthermore, this would offer only a regional solution in technologically advanced countries. It will be beyond the reach of developing countries.

2. Production of ${ }^{99} \mathrm{Mo}$ by fission of low-enriched ${ }^{235} \mathrm{U}$ for regional (not global) supply. Countries like Argentina, South Africa, Russia, India, Pakistan, Ukraine, etc. could do so. Some of them are already developing the methodology and producing appreciable quantities of fission ${ }^{99}$ Mo.

3. Enhanced production of ${ }^{99}$ Mo through the $(n, \gamma)$ reaction and intensified efforts to make use of the gel generator, as it is done today in a few developing countries.

4. Development of future technologies, e.g. production of ${ }^{99}$ Mo by fission of ${ }^{\text {nat }} \mathrm{U}$, using an accelerator based intense photon or spallation neutron source. The spallation neutron source would be very suitable also for the production of several therapeutic radionuclides via the $(n, p)$ reaction $[c f .119]$.

5. Enhanced production and application of ${ }^{123} \mathrm{I}$ in SPECT studies.

6. Enhanced application of PET technology using ${ }^{18} \mathrm{~F}$ and ${ }^{68} \mathrm{Ga}$ labelled compounds. Large amounts of ${ }^{18} \mathrm{~F}$ could possibly be produced by using large-sized $\mathrm{H}_{2}{ }^{18} \mathrm{O}$ targets and proton energies of up to $30 \mathrm{MeV}$ [ $c f$. 120]. For producing large quantities of ${ }^{68} \mathrm{Ge}$ (the parent of ${ }^{68} \mathrm{Ga}$ ) via the ${ }^{69} \mathrm{Ga}(p, 2 n)$-reaction, high-current targetry for gallium irradiation will be required (see discussion under Sect. 2.3). The generator preparation methodology itself has reached sophistication [ $c f .88,89]$.

Thus considerable efforts may be called upon to ensure the smooth running of patient care programmes.

\subsection{Research orientations}

For research studies, the demand for longer lived positronemitting radionuclides, which have passed the stage of laboratory scale production and clinical evaluation, e.g. ${ }^{64} \mathrm{Cu}$, ${ }^{86} \mathrm{Y},{ }^{89} \mathrm{Zr}$ and ${ }^{124} \mathrm{I}$, will certainly increase. The same may be true for other potentially useful positron emitters, such as ${ }^{55} \mathrm{Co},{ }^{71} \mathrm{As},{ }^{72} \mathrm{As}$ and ${ }^{73} \mathrm{Se}$. If the demands for those radionuclides increase further, it may become incumbent to intensively search for intermediate energy production routes leading to higher yields and purity.

With regard to quantification of SPECT-radiopharmaceuticals, an analogue approach is applied which involves the use of a positron-emitting nuclide of the chemical element of the SPECT radionuclide. Thus for quantification of several ${ }^{99 \mathrm{~m}}$ Tc-radiopharmaceuticals, labelling of the compound was carried out using the positron emitting radionuclide ${ }^{94 \mathrm{~m}} \mathrm{Tc}\left(T_{1 / 2}=52 \mathrm{~min}\right)$ followed by a PET measurement. If the shortage of ${ }^{99 \mathrm{~m}} \mathrm{Tc}$ becomes acute, it is likely that ${ }^{123}$ I-radiopharmaceuticals will play a more important role in the future than today. For quantification of those radiopharmaceuticals, resort may have to be made to a short-lived positron emitting radioiodine, e.g. ${ }^{120} \mathrm{I}\left(T_{1 / 2}=1.3 \mathrm{~h}\right)$.

An important application of positron emitters is in quantification of radiation dose in internal radionuclide therapy. 
Combining a positron-emitting isotope of an element together with a therapeutic radioisotope of the same element, it is possible to measure the uptake kinetics by PET imaging, thereby allowing an accurate dosimetric calculation related to therapy. The principle was first applied in the case of internal therapy with ${ }^{90} \mathrm{Y}\left(T_{1 / 2} 2.7 \mathrm{~d}\right)$ after mixing it with the positron emitter ${ }^{86} \mathrm{Y}\left(T_{1 / 2}=14.7 \mathrm{~h}\right)[c f$. 121]. This concept is finding increasing application. A $\beta^{-}$(or Auger electron) and $\beta^{+}$emitting pair of radionuclides of the same element is now termed as a theragnostic pair [cf. 64]. There are several such pairs, e.g. ${ }^{89} \mathrm{Sr}\left(T_{1 / 2}=50.0 \mathrm{~d}, \beta^{-}\right) /{ }^{83} \mathrm{Sr}$ $\left(T_{1 / 2}=32.2 \mathrm{~h}, \beta^{+}\right) ;{ }^{131} \mathrm{I}\left(T_{1 / 2}=8.0 \mathrm{~d}, \beta^{-}\right) /{ }^{124} \mathrm{I}\left(T_{1 / 2}=4.18 \mathrm{~d}\right.$, $\left.\beta^{+}\right) ;{ }^{47} \mathrm{Sc}\left(T_{1 / 2}=3.35 \mathrm{~d}, \beta^{-}\right) /{ }^{44} \mathrm{Sc}\left(T_{1 / 2}=3.9 \mathrm{~h}, \beta^{+}\right) ;{ }^{67} \mathrm{Cu}$ $\left(T_{1 / 2}=2.6 \mathrm{~d}, \beta^{-}\right) /{ }^{64} \mathrm{Cu}\left(T_{1 / 2}=12.7 \mathrm{~h}, \beta^{+}\right) ;{ }^{67} \mathrm{Ga}\left(T_{1 / 2}=\right.$ $3.3 \mathrm{~d}$, Auger electrons $) /{ }^{68} \mathrm{Ga}\left(T_{1 / 2}=67.6 \mathrm{~min}, \beta^{+}\right)$and ${ }^{111} \mathrm{In}$ $\left(T_{1 / 2}=2.8 \mathrm{~d}\right.$, Auger electrons $) /{ }^{110 \mathrm{~g}}$ In $\left(T_{1 / 2}=1.1 \mathrm{~h}, \beta^{+}\right)$. Further development of those pairs would demand considerable efforts which, however, would depend on demonstrated novel applications based on a combination of PET imaging and targeted therapy.

Regarding internal radiotherapy, presently a shift is taking place from the use of $\beta^{-}$particle emitters to Auger electron and $\alpha$-particle emitters which induce more cellular effects. Several radionuclides are at the development stage (see above, Sect. 3.2), but once the principles have been established, the demands for those radionuclides will increase. Many of them are low-lying, highly converted, high spin states and are difficult to produce. Versatile nuclear routes will have to be harnessed, involving also intermediate energy reactions or even heavy-ion induced reactions. In short, elegant interdisciplinary approaches will be needed to obtain the desired radionuclides in high yield and purity.

A new perspective of medical radionuclides is emerging through extremely significant developments that are currently taking place in organ imaging. The dynamic and quantitative nature of PET (and recently to some extent also SPECT) is being coupled with X-ray tomography (CT) and magnetic resonance imaging (MRI) to provide a highly powerful combination of systems for organ imaging. The radionuclides of potential interest for the latter combination are considered below.

In MRI the elements Mn and Gd are often used as contrast agents. If a positron-emitting radionuclide is introduced in the system, the high-resolution of MRI and the quantitative nature of PET could lead to very high quality imaging. In the case of manganese the positron emitting radionuclide ${ }^{51} \mathrm{Mn}\left(T_{1 / 2}=46.2 \mathrm{~min}\right)$ has been suggested [ $\left.c f .122,123\right]$. Regarding gadolinium, no positron-emitting radionuclide is available. However, it has been demonstrated that this element could be converted to a so-called "intelligent (responsive) agent" [ $c f .124]$ by chemically binding it with a metal like $\mathrm{Cu}$ through pyridine [125]; This considerably increases the contrast. Now if copper could be a positron emitter, e.g. ${ }^{64} \mathrm{Cu}$, PET and MRI could be advantageously combined. A newer concept involves the conversion of a transition metal complex from the dia- to paramagnetic state (spin crossover) which can be used as a contrast agent [ $c f .124-$ 127]. The metals of interest are $\mathrm{Fe}$ and $\mathrm{Ni}$ and the potentially useful positron emitting radionuclides could be ${ }^{52} \mathrm{Fe}$ $\left(T_{1 / 2}=8.3 \mathrm{~h}\right)$ and ${ }^{57} \mathrm{Ni}\left(T_{1 / 2}=36.0 \mathrm{~h}\right)$, respectively. In view of the increasing interest in multimode imaging, the need for further development of suitable novel positron emitters will certainly increase.

Another long-term perspective of radionuclide technology could involve an intensive combination of radioactivity and nanotechnology. In recent years, the latter technology has made tremendous progress and its applications are now in many fields, including nuclear energy technology [ $c f .128]$. Also in medical radionuclide research, nanotechnology has found some connection, e.g. in production of a radionuclide for nanobioscience application [ $c f .129$ ], in construction of a generator column using a nanomaterial $[c f .130]$ and in retention of the recoiling daughter in an in vivo generator used in alpha radionuclide therapy [cf. 131]. Similarly, nanotargeted materials are finding increasing applications in tumour imaging and tumour therapy (for recent reviews $c f$. $[132,133]$ ). The types of needed radionuclides are generally the same as in conventional diagnosis and therapy described above.

\section{Concluding remarks}

It should be mentioned that also in the future the radionuclide production technology will strongly depend on research reactors as well as small and medium-sized cyclotrons with energies up to about $30 \mathrm{MeV}$. For production of many emerging radionuclides, however, intermediateenergy, high-intensity accelerators with proton energies up to about $100 \mathrm{MeV}$ will be required. Furthermore, there will be a need for higher energy facilities to accelerate also deuterons, ${ }^{3} \mathrm{He}$ and ${ }^{4} \mathrm{He}$ particles in order to extend the range of production and to improve the radionuclidic purity. In particular the ${ }^{4} \mathrm{He}$ particle beam may be quite advantageous for producing many of the therapeutic radionuclides. Needless to say, that highly qualified personnel with expertise in interdisciplinary areas of physics, chemistry, biology, medicine and engineering will always be needed to maintain, nurture and further develop this sophisticated technology for the benefit of human beings.

Acknowledgment. The author is grateful to many colleagues, in particular Prof. H. H. Coenen, Prof. F. Rösch, Dr. F. Tárkányi, and Dr. B. Scholten for stimulating discussions and critical comments. $\mathrm{S}$. Spellerberg is acknowledged for his help in the preparation of this manuscript.

\section{References}

1. Stöcklin, G., Qaim, S. M., Rösch, F.: The impact of radioactivity on medicine. Radiochim. Acta 70/71, 249-272 (1995).

2. Manual for reactor produced radioisotopes. IAEA-TECDOC1340 (2003), pp. 1-251.

3. Mirzadeh, S., Mausner, L. F., Garland, M. A.: Reactor-produced medical radionuclides. In: Handbook of Nuclear Chemistry. $2^{\text {nd }}$ Edn., Vol. 4 (Vertes, A., Nagy, S., Klencsár, Z., Lovas, R. G., Rösch, F., eds.), Springer, Dordrecht, The Netherlands (2011), pp. 1857-1902.

4. Qaim, S. M.: Cyclotron production of medical radionuclides. In: Handbook of Nuclear Chemistry. $2^{\text {nd }}$ Edn., Vol. 4 (Vertes, A., Nagy, S., Klencsár, Z., Lovas, R. G., Rösch, F., eds.), Springer, Dordrecht, The Netherlands (2011), pp. 1903-1933.

5. Qaim, S. M., Coenen, H. H.: Produktion pharmazeutisch relevanter Radionuklide. Pharm. Unser. Zeit 34, 460-466 (2005).

6. Karelin, Ye. A., Efimov, V. N., Filimonov, V. T., Kuznetsov, R. A., Revyakin, Yu. L., Andreev, O. I., Zhemkov, I. Yu., Bukh, V. G., 
Lebedev, V. M., Spiridonov, Ye. N.: Radionuclide production using a fast flux reactor. Appl. Radiat. Isot. 53, 825-827 (2000).

7. Tomar, B. S., Steinebach, O. M., Terpstra, B. E., Bode, P., Wolterbeek, H. T.: Studies on production of high specific activity ${ }^{99} \mathrm{Mo}$ and ${ }^{90} \mathrm{Y}$ by Szilard Chalmers reaction. Radiochim. Acta $\mathbf{9 8}$, 499-506 (2010).

8. Boyd, R. E.: The gel generator: a viable alternative source of ${ }^{99 \mathrm{~m}} \mathrm{Tc}$ for nuclear medicine. Appl. Radiat. Isot. 48, 1027-1033 (1997).

9. Rösch, F., Knapp, F. F.: Radionuclide generators. In: Handbook of Nuclear Chemistry. $2^{\text {nd }}$ Edn., Vol. 4 (Vertes, A., Nagy, S., Klencsár, Z., Lovas, R. G., Rösch, F., eds.), Springer, Dordrecht, The Netherlands (2011), pp. 1935-1976 (2011)

10. van der Marek, S. C., Koning, A. J., Charlton, E. K.: The options for future production of the medical isotope ${ }^{99}$ Mo. Eur. J. Nucl. Med. Mol. Imaging 37, 1817-1820 (2010).

11. Tárkányi, F., Qaim, S. M., Stöcklin, G., Sajjad, M., Lambrecht, R. M., Schweickert, H.: Excitation functions of $(p, 2 n)$ and $(p, p n)$ reactions and differential and integral yields of ${ }^{123} \mathrm{I}$ in proton induced nuclear reactions on highly enriched ${ }^{124} \mathrm{Xe}$. Appl. Radiat. Isot. 42, 221-228 (1991).

12. Hermanne, A., Tárkányi, F., Tákacs, S., Adam-Rebeles, R., Ignatyuk, A., Spellerberg, S., Schweickert, H.: Limitation of the long-lived ${ }^{121} \mathrm{Te}$ contaminant in production of ${ }^{123} \mathrm{I}$ through the ${ }^{124} \mathrm{Xe}(p, x)$ route. Appl. Radiat. Isot. 69, 358-368 (2011).

13. Qaim, S. M., Clark, J. C., Crouzel, C., Guillaume, M., Helmeke, H. J., Nebeling, B., Pike, V. W., Stöcklin, G.: PET radionuclide production. In: Radiopharmaceuticals for Positron Emission Tomography - Methodological Aspects. (Stöcklin, G. and Pike, V. W., eds.), Kluwer, Dordrecht, The Netherlands (1993), pp. $1-43$.

14. Meyer, G.-J., Coenen, H. H., Waters, S. L., Langström, B., Cantineau, R., Strijckmans, K., Vaalburg, W. Halldin, C., Crouzel, C., Mazière, B., Luxen, A.: Quality assurance and quality control of short-lived radiopharmaceuticals for PET. In: Radiopharmaceuticals for Positron Emission Tomography - Methodological Aspects. (Stöcklin, G. and Pike, V. W., eds.) Kluwer, Dordrecht, The Netherlands (1993), pp. 91-150.

15. Filosofov, D. V., Garland, M., John, K. D., Knapp Jr., F. F., Kuznetsov, R., Mausner, L., Mirzadeh, S., Pillai, M. R. A., Ponsard, B., Rösch, F., Ruth, T. J., Samanta, S. K.: Production of long-lived parent radionuclides for generators: ${ }^{68} \mathrm{Ge},{ }^{82} \mathrm{Sr},{ }^{90} \mathrm{Sr}$ and ${ }^{188} \mathrm{~W}$. IAEA Radioisotopes and Radiopharmaceuticals Series No. 2, IAEA, Vienna, Austria (2008), pp. 1-108.

16. Ruth, T. J., Wolf, A. P.: Absolute cross sections for the production of ${ }^{18} \mathrm{~F}$ via the ${ }^{18} \mathrm{O}(p, n){ }^{18} \mathrm{~F}$ reaction. Radiochim. Acta 26, 21-24 (1979).

17. Coenen, H. H., Klatte, B., Knöchel, A., Schüller, M., Stöcklin, G.: Preparation of nca $\left[17-{ }^{18} \mathrm{~F}\right]$-fluoro-heptadecanoic acid in high yields via aminopolyether supported, nucleophilic fluorination. J. Label. Compd. Radiopharm. 23, 455-467 (1986).

18. Hamacher, K., Coenen, H. H., Stöcklin, G.: Efficient stereospecific synthesis of no-carrier-added $2-\left[{ }^{18} \mathrm{~F}\right]$-fluoro-2-deoxy-D-glucose using aminopolyether supported nucleophilic substitution. J. Nucl. Med. 27, 235-238 (1986).

19. Qaim, S. M.: Therapeutic radionuclides and nuclear data. Radiochim. Acta 89, 297-302 (2001).

20. Lebedev, N. A., Novgorodov, A. F., Misiak, R., Brockmann, J., Rösch, F.: Radiochemical separation of no-carrier-added ${ }^{177} \mathrm{Lu}$ as produced via the ${ }^{176} \mathrm{Yb}(n, \gamma){ }^{177} \mathrm{Yb} \rightarrow{ }^{177} \mathrm{Lu}$ process. Appl. Radiat. Isot. 53, 421-425 (2000).

21. Hussain, M., Sudár, S., Aslam, N. M., Shah, H. A., Malik, A. A., Qaim, S. M.: A comprehensive evaluation of charged-particle data for production of the therapeutic radionuclide ${ }^{103} \mathrm{Pd}$. Appl. Radiat. Isot. 67, 1842-1854 (2009).

22. Lambrecht, R. M., Mirzadeh, S.: Cyclotron isotopes and radiopharmaceuticals. XXXV. Astatine-211. Int. J. Appl. Radiat. Isot. 36, 443-450 (1985).

23. Proceedings of the Workshop on Non-standard Positron Emitters, Aachen (2007). Quarterly J. Nucl. Med. Mol. Imaging (Spec. Issue) 52, 101-206 (2008).

24. Qaim, S. M., Huclier-Markai, S. (eds.): Innovative positron emitting radionuclides. Radiochim. Acta 89, 607-678 (2011).
25. Qaim, S. M.: Development of novel positron emitters for medical applications: nuclear and radiochemical aspects. Radiochim. Acta 99, 611-625 (2011).

26. Qaim, S. M.: Decay data and production yields of some nonstandard positron emitters used in positron emission tomography. Quarterly J. Nucl. Med. Mol. Imaging 52, 111-120 (2008).

27. Qaim, S. M.: Radiochemical determination of nuclear data for theory and applications. J. Radioanal. Nucl. Chem. 284, 489-505 (2010).

28. Aslam, M. N., Sudár, S., Hussain, M., Malik, A. A., Shah, H. A., Qaim, S. M.: Charged particle induced reaction cross section data for production of the emerging medically important positron emitter ${ }^{64} \mathrm{Cu}$ : a comprehensive evaluation. Radiochim. Acta 97, 669-686 (2009).

29. Qaim, S. M., Bisinger, T., Hilgers, K., Nayak, D., Coenen, H. H. Positron emission intensities in the decay of ${ }^{64} \mathrm{Cu},{ }^{76} \mathrm{Br}$ and ${ }^{124} \mathrm{I}$. Radiochim. Acta 95, 67-73 (2007).

30. Szelecsényi, F., Blessing, G., Qaim, S. M.: Excitation functions of proton induced nuclear reactions on enriched ${ }^{61} \mathrm{Ni}$ and ${ }^{64} \mathrm{Ni}$ : possibility of production of no-carrier-added ${ }^{61} \mathrm{Cu}$ and ${ }^{64} \mathrm{Cu}$ at a small cyclotron. Appl. Radiat. Isot. 44, 575-580 (1993).

31. McCarthy, D. W., Shefer, R. E., Klinkowstein, R. E., Bass, L. A., Margeneau, W. H., Cutler, C. S., Anderson, C. J., Welch, M. J.: Efficient production of high specific activity ${ }^{64} \mathrm{Cu}$ using a biomedical cyclotron. Nucl. Med. Biol. 24, 35-43 (1997).

32. Szajek, L. P., Meyer, W., Plascjak, P., Eckelman, W. C.: Semiremote production of $\left[{ }^{64} \mathrm{Cu}\right] \mathrm{CuCl}_{2}$ and preparation of high specific activity $\left[{ }^{64} \mathrm{Cu}\right] \mathrm{Cu}$-ATSM for PET studies. Radiochim. Acta 93, 239-244 (2005).

33. Obata, A., Kasamatsu, S., McCarthy, D. W., Welch, M. J., Saji, H., Yonekura, Y., Fujibayashi, Y.: Production of therapeutic quantities of ${ }^{64} \mathrm{Cu}$ using a $12 \mathrm{MeV}$ cyclotron. Nucl. Med. Biol. 30, 535-539 (2003).

34. Avila-Rodriguez, M. A., Nye, J. A., Nickles, R. J.: $\quad$ Simultaneous production of high specific activity ${ }^{64} \mathrm{Cu}$ and ${ }^{61} \mathrm{Co}$ with 11.4 MeV protons on enriched ${ }^{64} \mathrm{Ni}$ nuclei. Appl. Radiat. Isot. $\mathbf{6 5}$, 1115-1120 (2007).

35. Sadeghi, M., Amiri, M., Roshanfarzad, P., Avila, M., Tenreiro, C.: Radiochemical studies relevant to the no-carrier-added production of ${ }^{61,64} \mathrm{Cu}$ at a cyclotron. Radiochim. Acta 96, 399-402 (2008).

36. Le, V. S., Howse, J., Zaw, M., Pellegrini, P., Katsifis, A., Greguric, I., Weiner, R.: Alternative method for ${ }^{64} \mathrm{Cu}$ radioisotope production. Appl. Radiat. Isot. 67, 1324-1331 (2009).

37. Abbas, K., Kozempel, J., Bonardi, M., Groppi, F., Alfarano, A., Holzwarth, U., Simonelli, F., Hofmann, H., Horstmann, W., Menapace, E., Lešetický, L., Gibson, N.: Cyclotron production of ${ }^{64} \mathrm{Cu}$ by deuteron irradiation of ${ }^{64} \mathrm{Zn}$. Appl. Radiat. Isot. 64, 1001-1005 (2006).

38. Kozempel, J., Abbas, K., Simonelli, F., Zampese, M., Holzwarth, U., Gibson, N., Lešetický, L.: A novel method for n.c.a. ${ }^{64} \mathrm{Cu}$ production by the ${ }^{64} \mathrm{Zn}(\mathrm{d}, 2 \mathrm{p}){ }^{64} \mathrm{Cu}$ reaction and dual ion-exchange column chromatography. Radiochim. Acta 95, 75-80 (2007).

39. Szeleczényi, F., Steyn, G. F., Kovács, Z., Vermeulen, C., van de Meulen, N. P., Dolley, S. G., van der Walt, T. N., Suzuki, K., Mukai, K.: Investigation of the ${ }^{66} \mathrm{Zn}(p, 2 p n)^{64} \mathrm{Cu}$ and ${ }^{68} \mathrm{Zn}(p, x){ }^{64} \mathrm{Cu}$ nuclear processes up to $100 \mathrm{MeV}$ : production of ${ }^{64} \mathrm{Cu}$. Nucl. Instrum. Methods B 240, 625-637 (2005).

40. Scholten, B., Kovács, Z., Tárkányi, F., Qaim, S. M.: Excitation functions of ${ }^{124} \mathrm{Te}(p, x n)^{124,123}$ I reactions from 6 to $31 \mathrm{MeV}$ with special reference to the production of ${ }^{124} \mathrm{I}$ at a small cyclotron. Appl. Radiat. Isot. 46, 255-259 (1995).

41. Qaim, S. M., Hohn, A., Bastian, Th., El-Azoney, K. M., Blessing, G., Spellerberg, S., Scholten, B., Coenen, H. H.: Some optimisation studies relevant to the production of high-purity ${ }^{124} \mathrm{I}$ and ${ }^{120 g} \mathrm{I}$ at a small-sized cyclotron. Appl. Radiat. Isot. 58, 69-78 (2003).

42. Sheh, Y., Koziorowski, J., Balatoni, J., Lom, C., Dahl, J. R., Finn, R. D.,: Low energy cyclotron production and chemical separation of no carrier added iodione-124 from a usable, enriched tellurium-124 dioxide/aluminium oxide solid solution target. Radiochim. Acta 88, 169-173 (2000).

43. Glaser, M., Mackay, D. B., Ranicar, A. S. O., Waters, S. L., Brady, F., Luthra, S. K.: Improved targetry and production of ${ }^{124} \mathrm{I}$ for PET studies. Radiochim. Acta 92, 951-956 (2004). 
44. Sajjad, M., Bars, E., Nabi, H. A.: Optimisation of ${ }^{124}$ I production via ${ }^{124} \mathrm{Te}(p, n)^{124} \mathrm{I}$ reaction. Appl. Radiat. Isot. 64, 965-970 (2006).

45. Nye, J. A., Avila-Rodriguez, M. A., Nickles, R. J.: Production of $\left[{ }^{124} \mathrm{I}\right]$-iodine on an $11 \mathrm{MeV}$ cyclotron. Radiochim. Acta 94, 213-216 (2006).

46. Rösch, F., Qaim, S. M., Stöcklin, G.: Nuclear data relevant to the production of the positron emitting radioisotope ${ }^{86} \mathrm{Y}$ via the ${ }^{86} \mathrm{Sr}(p, n)$ - and ${ }^{\text {nat }} \mathrm{Rb}\left({ }^{3} \mathrm{He}, x n\right)$-processes. Radiochim. Acta 61, 1-8 (1993).

47. Rösch, F., Qaim, S. M., Stöcklin, G.: Production of the positron emitting radioisotope ${ }^{86} \mathrm{Y}$ for nuclear medical application. Appl. Radiat. Isot. 44, 677-681 (1993).

48. Kettern, K., Linse, K.-H., Spellerberg, S., Coenen, H. H., Qaim, S. M.: Radiochemical studies relevant to the production of ${ }^{86} \mathrm{Y}$ and ${ }^{88} \mathrm{Y}$ at a small-sized cyclotron. Radiochim. Acta 90, 845-849 (2002).

49. Reischle, G., Rösch, F., Machulla, H.-J.: Electrochemical separation and purification of yttrium-86. Radiochim. Acta 90, 225-228 (2002).

50. Yoo, J., Tang, L., Perkins, T. A., Rowland, D. J., Laforest, R., Lewis, J. S., Welch, M. J.: Preparation of high specific activity ${ }^{86} \mathrm{Y}$ using a small biomedical cyclotron. Nucl. Med. Biol. 32, 891-897 (2005).

51. Lukic, D., Tamburella, C., Buchegger, F., Beyer, G.-J., Comor, J. J., Seimbille, Y.: High efficient production and purification of ${ }^{86} \mathrm{Y}$ based on electrochemical separation. Appl. Radiat. Isot. 67, 523-529 (2009).

52. Park, L. S., Szajek, L. P., Wong, K. J., Plascjak, P. S., Garmestani, K., Googins, S., Eckelman, W. C., Carrasquillo, J. A., Paik, C. H.: Semi-automated ${ }^{86} \mathrm{Y}$ purification using a three column system. Nucl. Med. Biol. 31, 297-301 (2004).

53. Kandil, S. A., Scholten, B., Hassan, K. F., Hanafi, H. A., Qaim, S. M.: A comparative study on the separation of radioyttrium from Sr- and Rb-targets via ion-exchange and solvent extraction techniques, with special reference to the production of no-carrieradded ${ }^{86} \mathrm{Y},{ }^{87} \mathrm{Y}$ and ${ }^{88} \mathrm{Y}$ using a cyclotron. J. Radioanal. Nucl. Chem. 279, 823-832 (2009)

54. Avila-Rodriguez, M. A., Nye, J. A., Nickles, R. J.: Production and separation of non-carrier-added ${ }^{86} \mathrm{Y}$ from enriched ${ }^{86} \mathrm{Sr}$ targets. Appl. Radiat. Isot. 66, 9-13 (2008).

55. Sadeghi, M., Zali, A., Avila, M.: A novel method for radiochemical separation of radioyttrium from $\mathrm{Sr}$ targets using precipitation technique. Radiochim. Acta 98, 437-439 (2010).

56. Jennewein, M., Schmidt, A., Novgorodov, A. F., Qaim, S. M., Rösch, F.: A no-carrier-added ${ }^{72} \mathrm{Se} /{ }^{72} \mathrm{As}$ radionuclide generator based on distillation. Radiochim. Acta 92, 245-249 (2004).

57. Jennewein, M., Qaim, S. M., Kulkarni, P. V., Mason, R. P., Hermanne, A., Rösch, F.: A no-carrier-added ${ }^{72} \mathrm{Se} /{ }^{72} \mathrm{As}$ radionuclide generator based on solid phase extraction. Radiochim. Acta 92, 579-583 (2005).

58. Zhernosekov, K. P., Filosofov, D. V., Qaim, S. M., Rösch, F. A ${ }^{140} \mathrm{Nd} /{ }^{140} \mathrm{Pr}$ radionuclide generator based on physico-chemical transitions in ${ }^{140} \mathrm{Pr}$ complexes after electron capture decay of ${ }^{140}$ Nd-DOTA. Radiochim. Acta 95, 319-327 (2007).

59. Filosofov, K. P., Loktionova, N. S., Rösch, F.: A ${ }^{44} \mathrm{Ti} /{ }^{44} \mathrm{Sc}$ radionuclide generator for potential application of ${ }^{44} \mathrm{Sc}$-based PETradiopharmaceuticals. Radiochim. Acta 98, 149-156 (2010).

60. Pruszynski, M., Loktionova, N. S., Filosofov, D. V., Rösch, F.: Post-elution processing of ${ }^{44} \mathrm{Ti} /{ }^{44} \mathrm{Sc}$ generator-derived ${ }^{44} \mathrm{Sc}$ for chemical application. Appl. Radiat. Isot. 68, 1636-1641 (2010).

61. Daraban, L., Rebeles, R. A., Hermanne, A., Tárkányi, F., Takács, S.: Study of the excitation functions for ${ }^{43} \mathrm{~K},{ }^{43,44,44 m} \mathrm{Sc}$ and ${ }^{44} \mathrm{Ti}$ by proton irradiations of ${ }^{45} \mathrm{Sc}$ up to $37 \mathrm{MeV}$. Nucl. Instrum. Methods B 267, 755-759 (2009).

62. Rösch, F.: Radiolanthanides in endoradiotherapy: an overview. Radiochim. Acta 95, 303-311 (2007).

63. Mausner, L. F., Kolsky, K. L., Mease, R. C., Chinol, M., Meinken, G. E., Straub, R. F., Pietrelli, L., Steplewski, Z., Srivastava, S. C. Production and evaluation of ${ }^{47} \mathrm{Sc}$ for radioimmunotherapy. J. Label. Compds. Radiopharm. 32, 388-390 (1993).

64. Srivastava, S. C.: Paving the way to personalized medicine: production of some theragnostic radionuclides at Brookhaven National Laboratory. Radiochim. Acta 99, 635-640 (2011).
65. Ando, A., Ando, I., Tonami, N., Kinyua, S., Okamoto, N., Sugimoto, M., Fukuda, N., Matsumoto, S.: Production of ${ }^{105} \mathrm{Rh}-$ EDTMP and its bone accumulation. Appl. Radiat. Isot. 52, 211-215 (2000).

66. Kastleiner, S., Coenen, H. H., Qaim, S. M.: Possibility of production of ${ }^{67} \mathrm{Cu}$ at a small-sized cyclotron via the $(\mathrm{p}, \alpha)$ reaction on enriched ${ }^{70} \mathrm{Zn}$. Radiochim. Acta 84, 107-110 (1999).

67. Mirzadeh, S., Mausner, L. F., Srivastava, S. C.: Production of nocarrier-added ${ }^{67} \mathrm{Cu}$. Appl. Radiat. Isot. 37, 29-36 (1986).

68. Schwarzbach, R., Zimmermann, K., Bläuenstein, P., Smith, A., Schubiger, P. A.: Development of a simple and selective separation of ${ }^{67} \mathrm{Cu}$ from irradiated zinc for use in antibody labelling: a comparison of methods. Appl. Radiat. Isot. 46, 329-336 (1995).

69. Stoll, T., Kastleiner, S., Shubin, Yu. N., Coenen, H. H., Qaim, S. M.: Excitation functions of proton induced reactions on ${ }^{68} \mathrm{Zn}$ from threshold up to $71 \mathrm{MeV}$, with specific reference to the production of ${ }^{67} \mathrm{Cu}$. Radiochim. Acta 90, 309-313 (2002).

70. Kozempel, J., Abbas, K., Simonelli, F., Bulgheroni, A., Holzwarth, U., Gibson, N.: Preparation of ${ }^{67} \mathrm{Cu}$ via deuteron irradiation of ${ }^{70} \mathrm{Zn}$. Radiochim. Acta 100, 419-423 (2012).

71. Hussain, M., Sudár, S., Aslam, M. N., Malik, A. A., Ahmad, R., Qaim, S. M.: Evaluation of charged particle induced reaction cross section data for production of the important therapeutic radionuclide ${ }^{186}$ Re. Radiochim. Acta 98, 385-395 (2010).

72. Shigeta, N., Matsuoka, H., Osa, A., Koizumi, M., Izumo, M., Kobayashi, K., Hashimoto, K., Sekine, T., Lambrecht, R. M.: Production method of no-carrier-added ${ }^{186}$ Re. J. Radioanal. Nucl. Chem. 205, 85-92 (1996).

73. Lapi, S., Mills, W. J., Wilson, J., McQuarrie, S., Publicover, J., Schueller, M., Schlyer, D., Ressler, J. J., Ruth, T. J.: Production cross-sections of ${ }^{181-186} \mathrm{Re}$ isotopes from proton bombardment of natural tungsten. Appl. Radiat. Isot. 65, 345-349 (2007).

74. Bonardi, M. Groppi, F., Persico, E., Manenti, S., Abbas, K., Holzwarth, U., Simonelli, F., Alfassi, Z. B.: Excitation functions and yields for cyclotron production of radiorhenium via ${ }^{\text {nat }} \mathrm{W}(p, x n)^{181-186 \mathrm{~g}} \mathrm{Re}$ nuclear reactions and tests on the production of ${ }^{186 \mathrm{~g}} \mathrm{Re}$ using enriched ${ }^{186} \mathrm{~W}$. Radiochim. Acta 99, 1-11 (2011).

75. Apostolidis, C., Molinet, R., McGinley, J., Abbas, K., Möllenbeck, J., Morgenstern, A.: Cyclotron production of ${ }^{225} \mathrm{Ac}$ for targeted alpha therapy. Appl. Radiat. Isot. 62, 383-387 (2005).

76. Ermolaev, S. V., Zhuikov, B. L., Kokhanyuk, V. M., Matushko, V. L., Kalmykov, S. N., Aliev, R. A., Tananaev, I. G., Myasoedov, B. F.: Production of actinium, thorium and radium isotopes from natural thorium irradiated with protons up to $141 \mathrm{MeV}$. Radiochim. Acta 100, 223-229 (2012).

77. Weidner, J. W., Mashnik, S. G., John, K. D., Ballard, B., Birnbaum, E. R., Bitteker, L. J., Couture, A., Fassbender, M. E., Goff, G. S., Gritzo, R., Hemez, F. M., Runde, W., Ullmann, J. L., Wolfsberg, L. E., Nortier, F. M.: ${ }^{225} \mathrm{Ac}$ and ${ }^{223} \mathrm{Ra}$ production via $800 \mathrm{MeV}$ proton irradiation of natural thorium targets. Appl. Radiat. Isotopes, submitted, E-print: 1204.2299 (2012).

78. Bruland, O. S., Nilsson, S., Fischer, D. R., Larsen, R. H.: High linear energy transfer irradiation targeted to skeletal metastases by the $\alpha$-emitter ${ }^{223} \mathrm{Ra}$ : adjuvant or alternative to conventional modalities. Clin. Cancer Res. 12, 6250S (2006).

79. Morgenstern, A., Lebeda, O., Stursa, J., Bruchertseifer, F., Capote, R., McGinley, J., Rasmussen, G., Sin, M., Zielinska, B., Apostolidis, C.: Production of $\mathrm{U} / \mathrm{Th}$ for targeted therapy via proton irradiation of Pa. Anal. Chem. 80, 8763-8770 (2008).

80. Morgenstern, A., Lebeda, O., Stursa, J., Capote, R., Sin, M., Bruchertseifer, F., Zielinska, B., Apostolidis, C.: Cross sections of the reaction ${ }^{231} \mathrm{~Pa}(\mathrm{~d}, 3 \mathrm{n}){ }^{230} \mathrm{U}$ for the production of ${ }^{230} \mathrm{U} /{ }^{226} \mathrm{Th}$ for targeted $\alpha$ therapy. Phys. Rev. C 80, 054612 (2009).

81. Morgenstern, A., Apostolidis, C., Bruchertseifer, F., Capote, R., Gouder, T., Simonelli, F., Sin, M., Abbas, K.: Cross sections of the reaction $\left.{ }^{232} \mathrm{Th}(p, 3 n)\right)^{230} \mathrm{~Pa}$ for production of ${ }^{230} \mathrm{U}$ for targeted alpha therapy. Appl. Radiat. Isot. 66, 1275-1280 (2008).

82. Tárkányi, F., Hermanne, A., Tákacs, S., Rebeles, R. A., van den Winkel, P., Király, B., Ditrói, F., Ignatyuk, A. V.: Cross section measurements of the ${ }^{131} \mathrm{Xe}(p, n)$ reaction for production of the therapeutic radionuclide ${ }^{131} \mathrm{Cs}$. Appl. Radiat. Isot. 67, 1751-1757 (2009).

83. Hilgers, K., Shubin, Yu. N., Coenen, H. H., Qaim, S. M.: Experimental measurements and nuclear model calculations on the exci- 
tation functions of ${ }^{\text {nat }} \mathrm{Ce}\left({ }^{3} \mathrm{He}, x n\right)$ and ${ }^{141} \operatorname{Pr}(p, x n)$ reactions with special reference to production of the therapeutic radiocnuldide ${ }^{140} \mathrm{Nd}$. Radiochim. Acta 93, 553-560 (2005).

84. Hilgers, K., Coenen, H. H., Qaim, S. M.: Production of the therapeutic radionuclides ${ }^{193 \mathrm{~m}} \mathrm{Pt}$ and ${ }^{195 \mathrm{~m}} \mathrm{Pt}$ with high specific activity via $\alpha$-particle induced reactions on ${ }^{192} \mathrm{Os}$. Appl. Radiat. Isot. 66, 545-551 (2008).

85. Uddin, S., Scholten, B., Hermanne, A., Sudár, S., Coenen, H. H., Qaim, S. M.: Radiochemical determination of cross sections of $\alpha$-particle induced reactions on ${ }^{192} \mathrm{Os}$ for the production of the therapeutic radionuclide ${ }^{193 \mathrm{~m}} \mathrm{Pt}$. Appl. Radiat. Isot. 68, 2001-2006 (2010).

86. Uddin, M. S., Hermanne, A., Scholten, B., Spellerberg, S., Coenen, H. H., Qaim, S. M.: Small scale production of high purity ${ }^{193 m} \mathrm{Pt}$ by the ${ }^{192} \mathrm{Os}(\alpha, 3 n)$-process. Radiochim. Acta 99, 131-135 (2011).

87. Qaim, S. M., Spahn, I., Kandil, S. A., Coenen, H. H.: Nuclear data for production of ${ }^{88} \mathrm{Y},{ }^{140} \mathrm{Nd},{ }^{153} \mathrm{Sm}$ and ${ }^{169} \mathrm{Yb}$ via novel routes. Radiochim. Acta 95, 313-317 (2007).

88. Zhernosekov, K. P., Filosofov, D. V., Baum, R. P., Aschoff, P., Bihl, H., Razbash, A. A., Jahn, M., Jennewein, M., Rösch, F.: Processing of generator produced ${ }^{68} \mathrm{Ga}$ for medical application. J. Nucl. Med. 48, 1741-1748 (2007).

89. Asti, M., De Pietri, G., Fraternali, A., Grassi, E., Sghedoni, R., Fioroni, F., Rösch, F., Versari, A., Salvo, D.: Validation of ${ }^{68} \mathrm{Ge} /{ }^{68} \mathrm{Ga}$ generator processing by chemical purification for routine clinical application of ${ }^{68}$ Ga-DOTATOC. Nucl. Med. Biol. 35, 721-724 (2008).

90. Rösch, F., Riss, P. J.: The renaissance of the ${ }^{68} \mathrm{Ge} /{ }^{68} \mathrm{Ga}$ radionuclide generator initiates new developments in ${ }^{68} \mathrm{Ga}$ radiopharmaceutical chemistry. Curr. Top. Med. Chem. 10, 1633-1668 (2010).

91. Rösch, F., Baum, R. P.: Generator-based PET radiopharmaceuticals for molecular imaging of tumours: on the way to THERANOSTICS. Dalton Trans. 40, 6104-6111 (2011).

92. Berry, D. J., Ma, Y., Ballinger, J. R., Tavare, R., Koers, A., Sunassee, K., Zhou, T., Nawaz, S., Mullen, G. E. D., Hider, R. C., Blower, P. J.: Efficient bifunctional gallium-68 chelators for positron emission tomography: tris(hydroxypyridininone) ligands. Chem. Commun. 47, 7068-7070 (2011).

93. Notni, J., Simecek, J., Hermann, P., Wester, H.-J.: TRAP, a powerful and versatile framework for gallium-68 radiopharmaceuticals. Chem. - Eur. J. 17, 14718-14722 (2011).

94. Piel, H., Qaim, S. M., Stöcklin, G.: Excitation functions of $(p, x n)$-reactions on ${ }^{\text {nat }} \mathrm{Ni}$ and highly enriched ${ }^{62} \mathrm{Ni}$ : possibility of production of medically important radioisotope ${ }^{62} \mathrm{Cu}$ at a small cyclotron. Radiochim. Acta 57, 1-5 (1992).

95. Szelecsényi, F., Suzuki, K., Kovács, Z., Takei, M., Okada, K.: Production possibility of ${ }^{60,61,62} \mathrm{Cu}$ radioisotopes by alpha induced reactions on colbalt for PET studies. Nucl. Instrum. Methods B 187, 153-163 (2002)

96. Szelecsényi, F., Kovács, Z., Nagatsu, K., Fukumura, K., Suzuki, K., Mukai, K.: Investigations of direct production of ${ }^{68} \mathrm{Ga}$ with low energy multiparticle accelerator. Radiochim. Acta 100, 5-11 (2012).

97. Ruth, T. J.: Accelerating production of medical isotopes. Nature 457, 536-537 (2009).

98. Kudo, H., Muramatsu, H., Nakahara, H., Miyano, K., Kohno, I.: Fission fragment yields in the fission of ${ }^{232} \mathrm{Th}$ by protons of energies 8 to $22 \mathrm{MeV}$. Phys. Rev. C 25, 3011-3023 (1982).

99. Abbas, K., Holzwarth, U., Simonelli, F., Kozempel, J., Cydzik, I., Bulgheroni, A., Cotogno, G., Apostolidis, C., Bruchertseifer, F., Morgenstern, A.: Feasibility of ${ }^{99}$ Mo production by protoninduced fission of ${ }^{232} \mathrm{Th}$. Nucl. Instrum. Methods B 278, 20-25 (2012).

100. Crasta, R., Naik, H., Suryanarayana, S. V., Prajapati, P. M., Jagadisan, K. C., Thakara, S. V., Ganesh, S., Nimje, V. T., Mittal, K. C., Goswami, A.: Photo-neutron cross section of ${ }^{99}$ Mo. J. Radioanal. Nucl. Chem. 290, 367-373 (2011).

101. Nagai, Y., Hatsukawa, Y.: Production of ${ }^{99}$ Mo for nuclear medicine by ${ }^{100} \operatorname{Mo}(n, 2 n){ }^{99}$ Mo. J. Phys. Soc. Japan 78, 033201 Letter (2009).

102. Scholten, B., Lambrecht, R. M., Cogneau, M., Vera Ruiz, H., Qaim, S. M.: Excitation functions for the cyclotron production of ${ }^{99 m}$ Tc and ${ }^{99}$ Mo. Appl. Radiat. Isot. 51, 69-80 (1999).
103. Takács, S., Szúcs, Z., Tarkányi, F., Hermanne, A., Sonck, M.: Evaluation of proton induced reactions on ${ }^{100} \mathrm{Mo}$ : New cross sections for production of ${ }^{99 \mathrm{~m}} \mathrm{Tc}$ and ${ }^{99} \mathrm{Mo}$. J. Radioanal. Nucl. Chem. 257, 195-201 (2003)

104. Lebeda, O., Pruszynski, M.: New measurements of excitation functions for $(p, x)$ reactions on ${ }^{\text {nat }}$ Mo with special regard to the formation of ${ }^{95 \mathrm{~m}} \mathrm{Tc},{ }^{99 \mathrm{~m}} \mathrm{Tc}$ and ${ }^{99} \mathrm{Mo}$. Appl. Radiat. Isot. 68, 23552365 (2010).

105. Gagnon, K., Bénard, F., Kovacs, M., Ruth, T. J., Schaffer, P., Wilson, J. S., McQuarrie, S. A.: Cyclotron production of ${ }^{99 \mathrm{~m}} \mathrm{Tc}$ : Experimental measurement of the ${ }^{100} \mathrm{Mo}(p, x)^{99} \mathrm{Mo},{ }^{99 \mathrm{~m}} \mathrm{Tc}$ and ${ }^{99 \mathrm{~g}} \mathrm{Tc}$ excitation functions from 8 to $18 \mathrm{MeV}$. Nucl. Med. Biol. 38, 907916 (2011).

106. Tárkányi, F., Ditrói, F., Hermanne, A., Takács, S., Ignatyuk, A. V.: Investigation of activation cross-sections of proton induced nuclear reactions on ${ }^{\text {nat }} \mathrm{Mo}$ up to $40 \mathrm{MeV}$ : New data and evaluation. Nucl. Instrum. Methods B 280, 45-73 (2012).

107. Lebeda, O., Fikrle, M.: New measurements of excitation functions for $(d, x)$ reactions on ${ }^{\text {nat }}$ Mo with special regard to the formation of ${ }^{95 \mathrm{~m}} \mathrm{Tc},{ }^{99 \mathrm{~m}} \mathrm{Tc}$ and ${ }^{99} \mathrm{Mo}$. Appl. Radiat. Isot. 68, 24252432 (2010).

108. Tárkányi, F., Hermanne, A., Takács, S., Sonck, M., Szücs, Z., Kiraly, B., Ignatyuk, A. V.: Investigation of alternative production routes of ${ }^{99 \mathrm{~m}} \mathrm{Tc}$ : Deuteron induced reactions on ${ }^{100} \mathrm{Mo}$. Appl. Radiat. Isot. 69, 18-25 (2011).

109. Tárkányi, F., Ditrói, F., Takács, S., Kiraly, B., Hermanne, A. Sonck, M., Baba, M., Ignatyuk, A. V.: Investigation of activation cross-sections of deuteron induced nuclear reactions on natural Mo up to $50 \mathrm{MeV}$. Nucl. Instrum. Methods B 274, 1-25 (2012).

110. Guérin, B., Tremblay, S., Rodrigue, S., Rousseau, J. A., DumulonPerreault, V., Lecomte, R., van Lier, J. E., Zyuzin, A., van Lier, E. J.: Cyclotron production of ${ }^{99 \mathrm{~m}} \mathrm{Tc}$ : an approach to the medical isotope crisis. J. Nucl. Med. Newsline 51, 13N-16N (2010).

111. Morley, T. J., Dodd, M., Gagnon, K., Hanemaayer, V., Wilson, J., McQuarrie, S. A., English, W., Ruth, T. J., Bénard, F., Schaffer, P.: An automated module for the separation and purification of cyclotron-produced ${ }^{99 \mathrm{~m}} \mathrm{TcO}_{4}{ }^{-}$. Nucl. Med. Biol. 39, 551-559 (2012).

112. Celler, A., Hou, X., Bénard, F., Ruth, T. J.: Theoretical modelling of yields for proton-induced reactions on natural and enriched molybdenum targets. Phys. Med. Biol. 56, 5469-5484 (2011).

113. Lebeda, O., van Lier, E. J., Stursa, J., Ralis, J., Zyuzin, A.: Assessment of radionuclidic impurities in cyclotron produced ${ }^{99 \mathrm{~m}} \mathrm{Tc}$. Nucl. Med. Biol., DOI 10.1016/j.nucmedbio.2012.06.009.

114. Rösch, F., Novgorodov, A. F., Qaim, S. M.: Thermochromatographic separation of ${ }^{94 \mathrm{~m}} \mathrm{Tc}$ from enriched molybdenum targets and its large scale production for nuclear medical application. Radiochim. Acta 64, 113-120 (1994).

115. Chattopadhayay, S., Das, S. S., Das, M. K., Goomer, N. C.: Recovery of ${ }^{99 \mathrm{~m}} \mathrm{Tc}$ from $\mathrm{Na}_{2}\left[{ }^{99} \mathrm{Mo}\right] \mathrm{MoO}_{4}$ solution obtained from reactor-produced $(n, \gamma){ }^{99}$ Mo using tiny Dowex-1 column in tandem with a small alumina column. Appl. Radiat. Isot. 66, 18141817 (2008).

116. Gul, K., Hermanne, A., Mustafa, M. G., Nortier, F. M., Oblozinsky, P., Qaim, S. M., Scholten, B., Shubin, Yu., Takács, S., Tárkányi, F. T., Zhuang, Y.: Charged particle cross section database for medical radioisotope production: diagnostic radioisotopes and monitor reactions. IAEA-TECDOC-12311 (2009), pp. 1-285.

117. Qaim, S. M., Tárkányi, F., Capote, R. (Eds.): Nuclear data for the production of therapeutic radionuclides. IAEA Techn. Reports Series No. 473 (2011), pp. 1-358.

118. Tárkányi, F., Takács, S. Király, B., Szelecsényi, F., Andó, L., Bergman, J., Heselius, S. J., Hermanne, A., Shubin. Yu.N., Ignatyuk, A. V.: Excitation functions of ${ }^{3} \mathrm{He}$ - and $\alpha$-particle induced nuclear reactions on ${ }^{\text {nat }} \mathrm{Sb}$ for production of medically relevant ${ }^{123} \mathrm{I}$ and ${ }^{124} \mathrm{I}$ radioisotopes. Appl. Radiat. Isot. 67, 1001-1006 (2009).

119. Spahn, I., Coenen, H. H., Qaim, S. M.: Enhanced production possibility of the therapeutic radionuclides ${ }^{64} \mathrm{Cu},{ }^{67} \mathrm{Cu}$ and ${ }^{89} \mathrm{Sr}$ via $(n, p)$ reactions induced by fast spectral neutrons. Radiochim. Acta 92, 183-186 (2004).

120. Hess, E., Takács, S., Scholten, B., Tákányi, F., Coenen, H. H., Qaim, S. M.: Excitation function of the ${ }^{18} \mathrm{O}(p, n){ }^{18} \mathrm{~F}$ nuclear reaction from threshold up to $30 \mathrm{MeV}$. Radiochim. Acta 89, 3527-362 (2001). 
121. Herzog, H., Rösch, F., Stöcklin, G., Lueders, C., Qaim, S. M., Feinendegen, L. E.: Pharmacokinetics of ${ }^{86} \mathrm{Y}$-citrate in a patient with multiple bone metastases measured with PET and calculation of radiation dose in ${ }^{90} \mathrm{Y}$-citrate radiotherapy. J. Nucl. Med. 34, 2222-2226 (1993).

122. Klein, A. T. J., Rösch, F., Qaim, S. M.: Investigations of $\left.{ }^{50} \mathrm{Cr}(d, n)\right)^{51} \mathrm{Mn}$ and ${ }^{\text {nat }} \mathrm{Cr}(p, x){ }^{51} \mathrm{Mn}$ processes with respect to the production of the positron emitter ${ }^{51} \mathrm{Mn}$. Radiochim. Acta 88, 253-264 (2000).

123. Klein, A. T. J., Rösch, F., Coenen, H. H., Qaim, S. M.: Labelling of manganese-based magnetic resonance imaging (MRI) contrast agents with the positron emitter ${ }^{51} \mathrm{Mn}$, as exemplified by manganese-tetraphenyl-porphin-sulfonate $\left(\mathrm{MnTPPS}_{4}\right)$. Appl. Radiat. Isot. 62, 711-720 (2005).

124. Herges, R.: Spinschaltung und intelligente Kontrastmittel iㅡ der MRT. Nachr. Chem. 59, 817-821 (2011).

125. Que, E. L., Gianolio, E., Baker, S. L., Wong, A. P., Aime, S., Chang, C. J.: Copper-responsive magnetic resonance imaging contrast agents. J. Amer. Chem. Soc. 131, 8527-8536 (2009).

126. Frullano, L., Catana, C., Benner, T., Sherry, A. D., Caravan, P. Bimodal MR-PET agent for quantitative $\mathrm{pH}$ imaging. Angew. Chem. 122, $2432-2434$ (2010).

127. Venkatamarani, S., Jana, U., Dommaschk, M., Sönnichsen, F. D., Tuczek, F., Herges, R.: Magnetic bistability of molecules in ho- mogeneous solution at room temperature. Science 331, 445-448 (2011).

128. Shi, W., Yuan, L., Li, Z., Lan, J., Zhao, Y., Chai, Z.: Nanomaterials and nanotechnologies in nuclear energy chemistry. Radiochim. Acta 100, 727-736 (2012).

129. Simonelli, F., Abbas, K., Huu-Tai, P. C., Holzwarth, U., Cydzik, I.: Measurement of excitation functions for production of cerium radioisotopes by deuteron induced reactions on natural cerium for nanobioscience applications. Radiochim. Acta 98, 187-191 (2010).

130. Chakravarty, R., Shukla, R., Ram, R., Tyagi, A. K., Dash, A., Venkatesh, M.: Development of a nano-zirconia based ${ }^{68} \mathrm{Ge} /{ }^{68} \mathrm{Ga}$ generator for biomedical applications. Nucl. Med. Biol. 38, 575$583(2011)$.

131. Thijssen, L., Schaart, D. R., de Vries, D., Morgenstern, A., Bruchertseifer, F., Denkova, A. G.: Polymersomes as nano-carriers to retain harmful recoil nuclides in alpha radionuclide therapy: a feasibility study. Radiochim. Acta 100, 473-481 (2012).

132. Ting, G., Chang, C., Wang, H., Lee, T.: Nano-targeted radionuclides for cancer imaging and internal radiotherapy. J. Biomed. Biotechnol., Article ID 953537, 17 pages (2010).

133. Huang, W.-Y., Davis, J. J.: Multimodality and nanoparticles in medical imaging. Dalton Trans. 40, 6087-6103 (2011). 